Cite this: Mater. Horiz., 2014, 1, 379

\title{
Recent progress on graphene-based hybrid electrocatalysts
}

Received 11th March 2014

Accepted 28th March 2014

DOI: $10.1039 / \mathrm{c} 4 \mathrm{mh} 00040 \mathrm{~d}$

rsc.li/materials-horizons

\begin{abstract}
Bao Yu Xia, Ya Yan, Xin Wang* and Xiong Wen (David) Lou*
Graphene-based hybrid nanostructures have attracted increasing interest worldwide. Benefiting from their remarkable electrochemical catalytic properties derived from chemical compositions and synergetic effects of multi-functionalities, these graphene-based hybrid nanomaterials will play a significant role in cutting-edge innovation for novel electrocatalysts. In this review, we summarize recent progress in the design and synthesis of graphene-based hybrid nanomaterials with controlled shape, size, composition and structure, and their application as efficient electrocatalysts for energy related systems. We conclude this article with some future trends and prospects which are highlighted for further investigations on graphene-based nanomaterials as advanced electrocatalysts.
\end{abstract}

\section{Introduction}

Stimulated by the increasing demand for energy and pressing need for fossil fuel alternatives, researchers worldwide have been actively exploring new sustainable energy sources and technologies. ${ }^{1}$ Amongst the various possibilities, electrochemical energy conversion technology is considered one of the most viable solutions, in view of the fact that it is environmentally friendly, affords high power density and high stability. Furthermore, some electrochemical energy conversion technologies such as fuel cells can also provide high energy densities, making them promising technologies for the generation of sustainable and green energy. ${ }^{2}$

School of Chemical and Biomedical Engineering, Nanyang Technological University, 62 Nanyang Drive, Singapore, 637459. E-mail: wangxin@ntu.edu.sg; xwlou@ntu. edu.sg; davidlous8@gmail.com
Various electrochemical reactions are involved in these electrochemical technologies. In fuel cells, electrochemical fuel (hydrogen and alcohols) oxidation reactions (HOR and AOR) and oxygen reduction reaction (ORR) take place at the anode and the cathode, respectively. ${ }^{3}$ ORR and oxygen evolution reaction (OER) are also the two half-reactions in the discharging-charging process of rechargeable metal-air batteries. ${ }^{2}$ Besides OER, hydrogen evolution reaction (HER) is the other half-reaction involved in water splitting. ${ }^{4}$ All these electrochemical reactions require the presence of efficient electrocatalysts, which play an important role in determining the conversion efficiency of electrochemical systems. ${ }^{5}$ Pt-based electrocatalysts are most widely used in these electrochemical devices. However, high cost and low stability of noble metals limit their practical application in a large scale. Therefore, design and preparation of advanced alternative electrocatalysts with excellent performance and low cost are of great importance for the development of these electrochemical systems. ${ }^{6}$

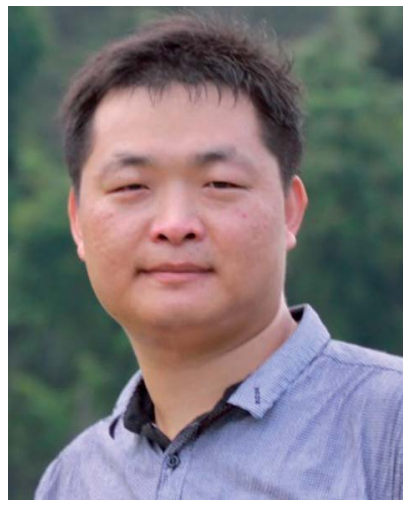

Bao Yu Xia received his Ph.D. degree in Materials Science and Engineering from Shanghai JiaoTong University (China) in 2010. He then moved to Nanyang Technological Univerisity, where he is a research fellow under the supervision of Prof. X. Wang and Prof. X. W. Lou. His research interests are in the areas of nanostructured electrocatalysts and their application in energy conversion.

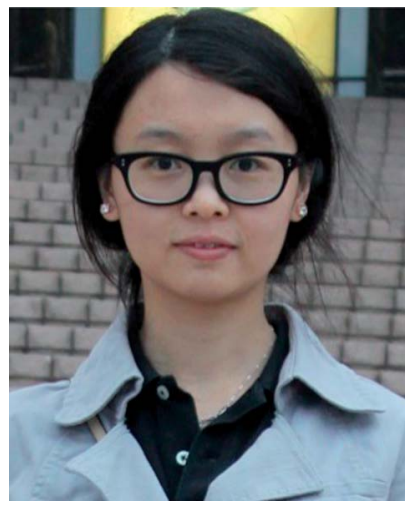

Ya Yan earned her bachelor's degree in Chemical Engineering from Northwest University (China) in 2010. She is currently pursuing a doctoral degree under the supervision of Prof. Xin Wang in the School of Chemical and Biomedical Engineering, Nanyang Technological University. Her research interests focus on the development of non-noble metal based nanocatalysts for electrochemical hydrogen evolution. 
In view of their abundance and stability, different carbon materials have been investigated for their potential application in electrochemical devices. ${ }^{7}$ Of particular interest is graphene, a new carbon material, which consists of a single atomic layer of carbon atoms. ${ }^{8}$ Its planar two-dimensional (2D) structure offers high surface area for the attachment of nanocrystals with good distribution, therefore preventing aggregation. Several highly desirable properties of graphene further favor their potential application. First, good electrical and optical properties enable potentially high performance as electron carriers in electrochemical applications. ${ }^{9}$ Second, good mechanical and thermal properties endow graphene-based composites with excellent thermal and mechanical stability which may be important in electronic devices or electrocatalytic systems involving heat release, such as fuel cells, metal-air batteries and the water splitting process. ${ }^{\mathbf{1 0 , 1 1}}$ Lastly, development of low cost and simple preparation methods also makes the processing of graphene-based nanocomposites simple and hence favors their practical applications. These nanocomposites have the potential to manifest not only unique properties of their individual components but also novel physical and chemical properties arisen from the synergetic effect between graphene and coupled nanostructures, eventually resulting in further improvement in performance. ${ }^{15}$ These promising properties together with the ease of processibility and functionalization make graphene-based functional materials ideal candidates for a variety of energy applications..$^{12-14}$

Some recent reviews have summarized the progress of graphene-based nanocomposites in energy storage and conversion fields such as solar cells, lithium-ion batteries, and supercapacitors. ${ }^{16-22}$ Graphene-based nanocomposites are highly promising as advanced catalysts with excellent performance. ${ }^{23-25}$ However, only a handful of reviews have focused on graphenebased hybrid nanomaterials for electrocatalysts. ${ }^{26,27}$ In this review, we focus on the synthesis of graphene-based hybrid nanomaterials and their electrocatalytic applications in fuel cells, $\mathrm{Li}-\mathrm{O}_{2}$ batteries and water splitting. To facilitate our

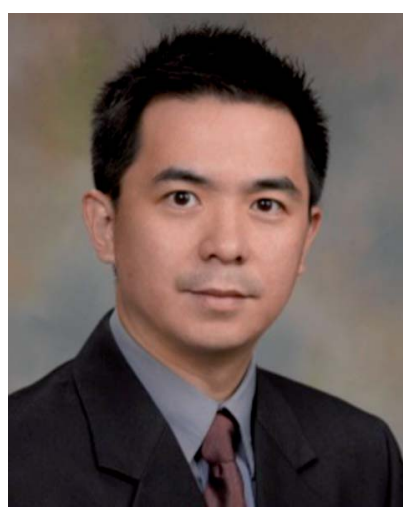

Xin Wang received his Bachelor (1994) and Master (1997) degrees in Chemical Engineering from Zhejiang University, and Ph. D. degree (2002) in Chemical Engineering from Hong Kong University of Science and Technology. He joined Nanyang Technological University as an assistant professor in 2005 and was promoted to associate professor in 2010. He has been working on electrocatalysis and electrochemical technologies for energy harvesting. He has authored more than 120 papers in refereed journals. He also holds six patents on novel nanomaterials for energy applications. discussion, a wide variety of graphene-based hybrid nanocomposites is grouped into three main categories: doped/ modified graphene, noble metal/graphene hybrids, and graphene/non-metal composites. For each category, a few important aspects will be discussed including advantages of structural characteristics, interaction between attached components and graphene, and their electrochemical performance as electrocatalysts. Further understanding and development of graphenebased hybrid electrocatalysts could therefore help to address the demand for new electrochemical energy devices and challenges for the widespread use of graphene-based electrocatalysts.

\section{Graphene as electrocatalysts}

\subsection{Graphene doped with non-metals as electrocatalysts}

Graphene is intrinsically inert, but starts possessing electrocatalytic activity after chemical modification or doping. ${ }^{28,29}$ Chemical doping involves replacement of carbon atoms in the hexagonal lattice by heteroatoms. Thus, the composition and the lattice structure of graphene are changed during the doping process. $^{30-32}$

Doping graphene with nitrogen $(\mathrm{N})$ atoms has made exceptional progress over the past decade and many promising material concepts have been demonstrated. ${ }^{33}$ Three types of $\mathrm{N}$ species including graphitic $\mathrm{N}$, pyridinic and pyrrolic $\mathrm{N}$ can be introduced into graphene, each of which affects its atomic charge distribution differently. Theoretical results on the effect of $\mathrm{N}$ doping into graphene have revealed that both atomic charge and spin density determine the material's catalytic properties. $^{35}$ Consequently, the mechanisms through which $\mathrm{N}$-doped graphene achieves activity enhancement also differ depending on the nature of $\mathrm{N}$ species present. ${ }^{34}$ It is thus important to determine the correlation between nitrogen bonding configuration in graphene and electrocatalytic activity.

Pyridinic and quaternary nitrogen species are generally considered as the active components of $\mathrm{N}$-doped graphene, but

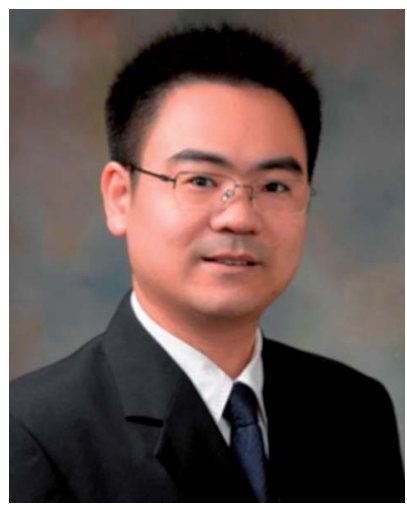

Xiong Wen (David) Lou received his B.Eng. (1st class honours) (2002) and M.Eng. (2004) degrees from the National University of Singapore. $\mathrm{He}$ obtained his Ph.D. degree in chemical engineering from Cornell University in 2008. He is currently an Associate Professor at Nanyang Technological University. As the lead author, he has published about 160 papers with total citation of $\sim 10500$ times according to ISI web of science and an H-index of $\sim 58$ as of April 2014. His current research is focused on design and synthesis of novel nanostructured materials for different applications in lithium-ion batteries, supercapacitors, electrocatalysis and photocatalysis. 
some doubts still exist. ${ }^{36,37}$ Selective doping of graphene has hence been undertaken to elucidate the ORR activity of different nitrogen species. To this end, Ruoff's group concluded that the electrocatalytic activity of $\mathrm{N}$-doped graphene is highly dependent on the graphitic-N content while pyridinic-N species improve the onset potential of ORR. ${ }^{34}$ On the other hand, Yasuda's work has recently shed some light on the origin of ORR activity in $\mathrm{N}$-doped graphene. More importantly, the authors also presented a method for synthesizing highly efficient $\mathrm{N}$-doped graphene electrocatalysts with tunable nitrogen active sites. ${ }^{38}$ Knights further determined that a low nitrogen doping level of $2.8 \%$ is sufficient to obtain high ORR activity via a $4 \mathrm{e}$ process (Fig. 1ac). ${ }^{39}$ This implies that the synergistic effect among N-containing species present contributes significantly to the enhanced ORR activity even at low doping levels. Two different ORR pathways (associative and dissociative) have been proposed for $\mathrm{N}$-doped graphene electrocatalysts in an alkaline medium. ${ }^{28}$ However, the detailed mechanism should be further explored.

In addition to the doped $\mathrm{N}$ content, the morphology of final graphene structures also plays a significant role in the electrochemical performance. For instance, Dai's recent work clearly indicates that the conjugation size of graphene is an important parameter. ${ }^{\mathbf{4 0 , 4 1}}$ On the other hand, the presence of abundant edges and functional groups is necessary for $\mathrm{N}$-doped colloidal graphene quantum dots (GQDs) to exhibit electrocatalytic activity. GQDs also provide unique opportunities for systematic investigation of mechanisms of ORR (Fig. 1d-f)..$^{42}$ Porous structures are also beneficial, given that such structures can possibly tune $\mathrm{N}$-doped graphene's band gap energy. ${ }^{43}$

The exfoliated graphene nanosheets produced by chemical methods have many edge and defect sites. ${ }^{\mathbf{4 4}}$ Such edge and defect sites are considered to serve as active sites for catalyzing chemical reactions. Furthermore, the planar structure of graphene nanosheets allows reactant access from both sides of the sheet. ${ }^{45}$ With these characteristics, graphene nanosheets are expected to be efficient cathode electrocatalysts for $\mathrm{Li}-\mathrm{O}_{2}$ batteries. ${ }^{4-49} \mathrm{~N}$ doping of graphene can modify the electronic property and provide more active sites for enhanced interaction between the carbon structure and other molecules, thus helping to improve the electrochemical performance in the $\mathrm{Li}-\mathrm{O}_{2}$ battery. ${ }^{50}$ Sun and coworkers first applied $\mathrm{N}$-doped graphene as the cathode electrocatalyst for $\mathrm{Li}-\mathrm{O}_{2}$ cells. $\mathrm{N}$-doped graphene has been shown to exhibit higher electrochemical activity compared to graphene in a non-aqueous electrolyte due to the defects and functional groups introduced by nitrogen doping. ${ }^{51}$

Besides the highly electronegative $\mathrm{N}$ atom, graphene has also been doped with other heteroatoms and subsequently investigated as metal-free electrocatalysts for ORR. ${ }^{52}$ Interestingly, graphene also exhibits significantly improved ORR catalytic activity when doped with heteroatoms including $\mathrm{S}$, Se and I with similar electronegativity as C. ${ }^{\mathbf{5 3} 54}$ Huang and coworkers have prepared S-doped graphene by annealing graphene oxide (GO) and benzyl disulfide in argon, and determined that under specific annealing conditions, S-doped graphene exhibits similar ORR onset potential and higher current density compared to commercial $\mathrm{Pt} / \mathrm{C}$ electrocatalysts. ${ }^{55} \mathrm{~S}$ has electronegativity close to that of $\mathrm{C}$, thus the enhanced ORR activity of S-doped graphene is attributed to the modifications in spin density instead of changes in atomic charge density as in B and $\mathrm{N}$ doping. ${ }^{56}$ Furthermore, the authors also speculated that the presence of $\mathrm{C}-\mathrm{S}$ bonds, formed mostly at the edges or defects of the graphene sheet, plays a crucial role as catalytic active sites for promotion of ORR. Explanations outlined above for S-doped graphene can also be extended to Se-doped graphene supported on carbon nanotubes (CNTs). ${ }^{57}$ The latter's improved ORR activity is also contributed by its evidently larger atomic size of Se compared to $\mathrm{C}$. This larger atomic size may cause higher strain at the graphene edges where heteroatoms are predominantly located; this may in turn facilitate charge localization and associated $\mathrm{O}_{2}$ chemisorption. Furthermore, Se has high polarizability and its electron lone pairs can easily interact with molecules in the surrounding electrolyte. These factors thus enable Se-doped graphene supported on CNTs (1 wt\% Se) to possess comparable ORR activity to $\mathrm{N}$-doped graphene at higher
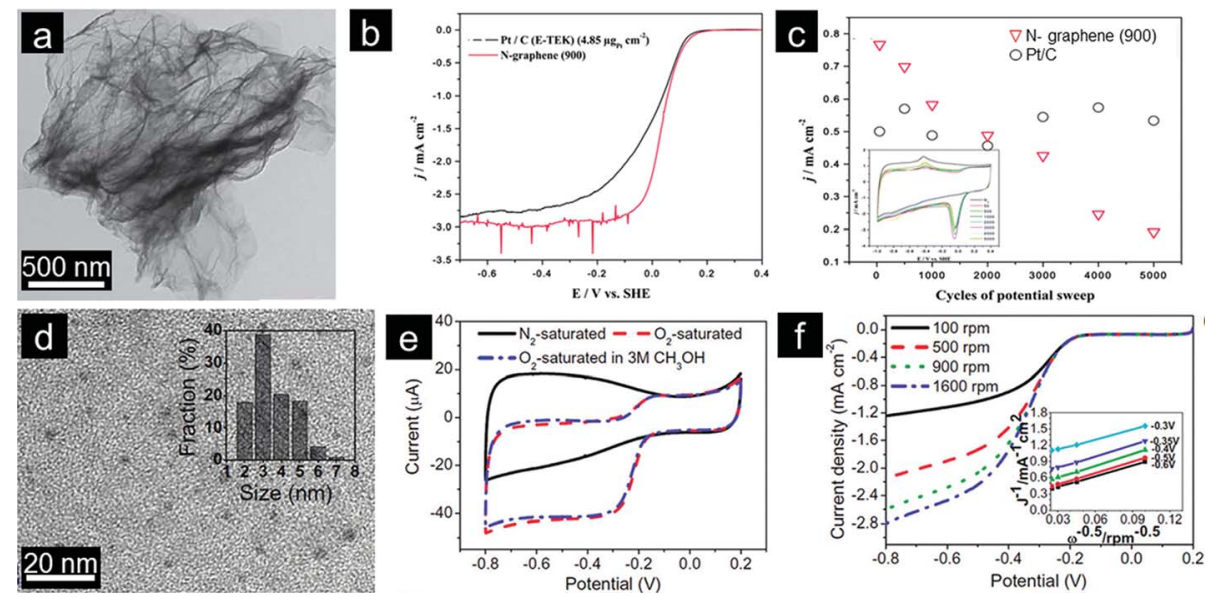

Fig. 1 (a) Typical TEM image and ( $b$ and c) electrochemical properties of N-doped graphene. (Reprinted with permission from ref. 39. Copyright@ 2011, Royal Society of Chemistry.) (d) TEM image with an inset showing the size distribution, (e) CVs and (f) rotating disk electrode (RDE) curves of GQDs in $0.1 \mathrm{M} \mathrm{KOH}$. (Reprinted with permission from ref. 49. Copyright $\odot$ 2012, American Chemical Society.) 
doping levels (4-8 wt\% N). For I-doped graphene prepared by annealing GO and $\mathrm{I}_{2}$, the content and more importantly the nature of I species present are crucial in determining electrochemical performance. Structures with a greater percentage of more negative $\mathrm{I}_{3}{ }^{-}$species result in higher ORR activity compared to those containing $\mathrm{I}_{5}{ }^{-}$species, owing to a greater degree of positive charge induced by the former. ${ }^{58}$

Graphene has also been doped by heteroatoms which are more electropositive (or more electron deficient) compared to carbon. In these cases, the positive charge is localized on the dopant itself which serves as the catalytic site for $\mathrm{O}_{2}$ chemisorption. P-doped (0.26 at\%) graphene has been prepared via pyrolysis of toluene and triphenylphosphine. Such P-doped graphene shows high electrocatalytic ORR activity, long-term stability, and excellent tolerance to cross-over effects of methanol in an alkaline medium. ${ }^{59}$ Additionally, a higher $\mathrm{P}$ doping level (1.16 at\%) improves ORR electrocatalytic activity and the ORR undergoes a $4 \mathrm{e}$ process. ${ }^{60}$ Boron is another prime candidate for doping of graphene, owing to its strong electron withdrawing capability. ${ }^{61}$ The resultant B-doped graphene exhibits excellent electrocatalytic activity towards ORR in alkaline electrolytes due to its unique structure and electronic properties. ${ }^{62}$

Considering the different electronegativities of various doping elements, a dual doping approach will be able to induce a unique electronic structure in graphene and achieve synergistic coupling between heteroatoms. ${ }^{29,63}$ Dual-doped graphene catalysts are thus expected to be catalytically more active than their singly doped counterparts. ${ }^{\mathbf{6 4 , 6 5}}$ In this regard, dual doping of graphene with two heteroatoms is currently one important strategy for tailoring chemical and physical properties of graphene for specific electrocatalytic applications. ${ }^{66,67}$ Dai and coworkers synthesized $\mathrm{B}, \mathrm{N}$ co-doped graphene with tunable composition by thermal annealing GO in the presence of boric acid and ammonia. ${ }^{68}$ The resultant $\mathrm{B}, \mathrm{N}$ co-doped graphene demonstrates superior electrocatalytic activity over commercial $\mathrm{Pt} / \mathrm{C}$ electrocatalysts for ORR in alkaline medium. ${ }^{69}$ Qiao and coworkers prepared B, N co-doped graphene with high purity and well-defined doping sites by a two-step doping method. Qiao's dual-doped-B, N graphene electrocatalysts exhibit better ORR electrocatalytic efficiency and greater stability compared to singly doped graphene. The improved performance is attributed to an enhanced synergistic coupling between $\mathrm{B}$ and $\mathrm{N}$ which facilitates the electrocatalytic ORR (Fig. 2a-c). ${ }^{70}$ Feng and Mullen prepared a three-dimensional (3D) B, N co-doped graphene aerogel in order to increase possible interactions between electrode materials and the electrolyte. This 3D B, N dual-doped graphene exhibits excellent electrochemical performance as a result of its high surface area, 3D macroporosity and high electrical conductivity. ${ }^{69,70}$ The synergistic effect between heteroatoms was also investigated for $\mathrm{N}$ and $\mathrm{S}$ dual-doped graphene with the porous structure. Again, the competitive ORR catalytic activity displayed by the dual-doped catalyst with pyrrolic/graphitic N-dominant structures was attributed to the synergistic effect of $\mathrm{N}$ and S co-doping. ${ }^{71,72}$ Qiao and coworkers also reported the synthesis of $\mathrm{S}$ and $\mathrm{N}$ dualdoped graphene with a mesoporous structure which shows excellent catalytic activity, comparable to that of the commercial
Pt/C catalyst, including a highly positive onset potential and very high kinetic limiting current. ${ }^{73}$ Outstanding performance of dual-doped graphene is explained by its dual activation of $\mathrm{C}$ atoms, as evidenced by both experimental measurements and quantum chemistry calculations (Fig. $2 \mathrm{~d}-\mathrm{f}$ ). ${ }^{73}$

\subsection{Graphene doped with transition metals as electrocatalysts}

Despite the superior ORR activity in alkaline media, electrocatalytic performance of graphene doped with non-metals is generally poor in acidic media, perhaps because of the presence of inactive surface sites. Some previous studies show that nongraphene carbon materials are able to exhibit high ORR activity in acidic media via the addition of metal species and formation of transition metal-N coordination structures. ${ }^{74-77}$ This idea was then extended to graphene with active sites for coordination with transition metals such as Fe and Co. It was expected that transition metal-graphene hybrid materials would lead to enhanced electrocatalytic performance. ${ }^{78}$ For example, Feng and Mullen synthesized Fe incorporated N-doped graphene which displays significantly enhanced electrocatalytic performance of high current density and stability. This Fe-N-graphene catalyst features a 4e transfer process and outperforms the commercial $\mathrm{Pt} / \mathrm{C}$ electrocatalyst toward ORR in both acidic and alkaline media. ${ }^{79}$ Similarly, Fe-doped graphene structures were also reported to be efficient electrocatalysts for ORR in acid media. ${ }^{\mathbf{8 0 , 8 1}}$ Chen and coworkers further designed 3D Fe-N coordination graphene/CNT structures to facilitate mass exchange and diffusion during the electrochemical ORR. Optimized doping level and synergistic coupling arising from the coordination between $\mathrm{N}$ and Fe favor ORR and boost electrochemical performance. Dong and coworkers reported the coordination of Co with $\mathrm{N}$-doped graphene as ORR electrocatalysts in alkaline media, showing high selectivity for the reaction. ${ }^{82} \mathrm{Co}$, Fe or even bimetallic (Co-Fe) embedded graphene hybrids can be prepared via thermal treatment of these salts with graphene. The transition metal-graphene hybrids prepared by this method also show promising ORR activity in acidic media. ${ }^{\mathbf{8 3 - 8 5}}$

\subsection{Functionalized graphene as electrocatalysts}

Although N-containing graphene is considered to be a promising candidate for ORR, significant challenges still impede its commercialization for fuel cell technology. A deeper understanding of the roles played by various nitrogen states during electrocatalysis and improvement on chemical doping procedures are some of the key issues which need to be solved before commercialization is feasible. ${ }^{86}$ In the latter case, most chemical doping approaches reported so far are complex and performed under harsh conditions, thus severely limiting their large scale utilization..$^{29,87} \mathrm{As}$ aforementioned, the enhanced ORR catalytic activity of $\mathrm{N}$-doped graphene is attributed to the electronaccepting ability of $\mathrm{N}$ atoms present. Given this understanding, researchers thus extended this concept to the functionalization of graphene with polyelectrolytes as metal-free electrocatalysts. ${ }^{\mathbf{8 8 - 9 0}}$ For example, Wang and coworkers reported that physical adsorption of poly-diallyldimethylammonium chloride (PDDA), 

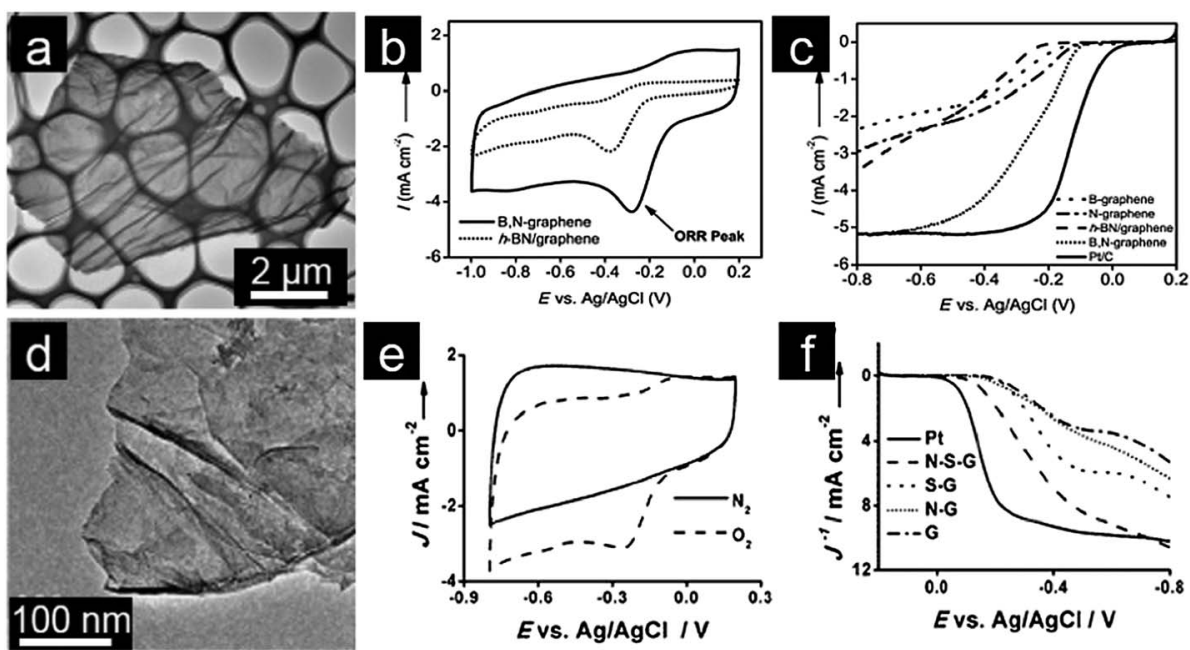

Fig. 2 (a) TEM image, (b) CVs and (c) RDE curves of B, N co-doped graphene. (Reprinted with permission from ref. 70. Copyright $\odot$ 2013, WILEY-VCH.) (d) TEM image, (e) CVs and (f) RDE curves of S, N co-doped graphene. (Reprinted with permission from ref. 73. Copyright $\odot$ 2012, WILEY-VCH.)

a positively charged polyelectrolyte with electron-withdrawing ability, onto $\mathrm{N}$-free graphene creates positive charges on the graphene surface via intermolecular charge transfer. ${ }^{91}$ The resultant PDDA-functionalized/adsorbed graphene manifests dramatically enhanced electrocatalytic activity toward ORR. This nanocomposite also exhibits better fuel selectivity and improved stability compared to the commercial $\mathrm{Pt} / \mathrm{C}$ catalyst. A similar observation was made for tridodecylmethylammonium chloride (TDMAC), another quaternary ammonium salt. ${ }^{93}$

On the other hand, Hou and coworkers designed aminofunctionalized graphene from graphene oxide in the presence of ammonia solution via a solvothermal approach. ${ }^{92}$ Their results show that the graphitic- and amino-type of nitrogen components determine the onset potential and the electron transfer number respectively, while the total content of graphitic and pyridinic $\mathrm{N}$ atoms is the key factor in enhancing current density for ORR. Dong and coworkers prepared neutral red covalently-functionalized graphene to improve the solubility and stability of graphene. ${ }^{94}$ Electrochemical impedance results further confirmed that neutral red functionalization can effectively accelerate electron transfer. The nanocomposites also exhibit excellent electrocatalytic activity toward uric acid oxidation due to the synergistic effect between neutral red and graphene. Transition metal phthalocyanine is also a promising candidate often used for functionalization of graphene as efficient ORR electrocatalysts. ${ }^{95-97}$ These nanocomposites are constructed by the strong $\pi-\pi$ interaction and exhibit high activity for ORR with excellent stability and selectivity.

\section{Graphene nanostructures as supports for noble metals}

Although graphene-based electrocatalysts have the advantage of significantly reducing the cost, their activity remains relatively low compared to noble metal based electrocatalysts. ${ }^{100}$ Noble metals and their alloys are still the best performing electrocatalysts for electrochemical reactions. Thus developing a new generation of low cost and highly active electrocatalysts is considered urgent for future electrochemical energy technologies. Moreover, majority of previous reports for metal-free electrocatalysts are related to ORR reaction at the cathode in basic media, probably due to faster reaction kinetics in alkaline media. But many electrochemical reactions are also performed in acidic media, such as the anode reactions in HOR and AOR fuel cells, and the research of novel electrocatalysts in acidic media is equally important. ${ }^{101}$

Despite the great advances in unsupported nanostructured noble metals for electrocatalysts, ${ }^{\mathbf{1 0 2}}$ the relatively low efficiency and high usage of noble metals in such unsupported noble metal electrocatalysts still limit their practical applications. This has triggered much research into improving Pt based electrocatalysts. Two important strategies are commonly employed, sometimes combined, to improve the electrochemical performance, stability and durability of these catalysts. The first is to develop specific morphologies. These shaped noble metal nanoparticles can lead to improved performance and also, in some cases, eliminate the need for supports thus avoiding the carbon corrosion problem. Another strategy is to design supports for better anchorage and enhanced interaction with metals. In this respect, graphene has emerged as a particular favorite as it possesses high surface area, low cost and enhanced conductivity compared to other traditional carbon supports for electrochemical applications. ${ }^{103,104}$ Furthermore, when alloy nanostructures are supported on graphene, it not only results in enhanced electrocatalytic activity and stability, but also allows for synergetic effects between metals and graphene, thereby reducing the noble metal content. ${ }^{105-107}$

\subsection{Graphene supported Pt-based electrocatalysts}

Pt-based electrocatalysts are the most popular choice for fuel oxidation at the anode and oxygen reduction at the cathode. ${ }^{5}$ 
Since around 2004, many efforts have been made towards obtaining Pt/graphene electrocatalysts with high electrochemical performance. Pt/graphene composites are generally prepared by the direct reduction of Pt precursors in the presence of reducing agents, such as $\mathrm{H}_{2}$, ethylene glycol, and $\mathrm{NaBH}_{4}$. Nature of Pt nanoparticles and the $\pi-\mathrm{d}$ hybridization interaction between $\mathrm{Pt}$ nanoparticles and graphene together determine the final catalytic performance. ${ }^{\mathbf{1 0 8}}$ Yoo and coworkers reported that strong interaction between Pt nanoparticles and graphene nanosheets (GNS) enables formation of subnanometer sized (below $0.5 \mathrm{~nm}$ ) Pt clusters (Fig. 3a). This allows the Pt nanoparticles to acquire specific electronic structures which in turn modifies the catalytic activity and gives unusually high methanol electro-oxidation activity. ${ }^{\mathbf{1 1 0}}$ Therefore, controllable deposition of $\mathrm{Pt}$ nanocrystals on graphene is highly desirable for enhanced performance. ${ }^{109}$

The morphology of Pt nanocrystals also affects the performance of these Pt/graphene catalysts. ${ }^{111}$ Wan and coworkers developed in situ preparation of hollow Pt nanocrystals decorated on graphene (Fig. $3 \mathrm{~b}$ ). Both the merits of hollow nanoparticles and the synergetic effect between Pt nanoparticles and graphene supports contribute to the enhanced electrocatalytic activity for methanol oxidation reaction (MOR, Fig. 3b and c) ${ }^{\mathbf{1 1 2}}$ Furthermore, one-dimensional (1D) Pt nanowires have also drawn much attention owing to their unique anisotropic structures, surface properties and excellent electrocatalytic activities. ${ }^{113}$ Ultrathin Pt nanowire arrays prepared on S-doped graphene (Fig. 3d), lead to 2-3 times higher catalytic activities toward the oxygen reduction and methanol oxidation reaction compared with the commercial Pt/C catalyst (Fig. 3e). ${ }^{\mathbf{1 1 4}} \mathrm{A}$ branched Pt nanowire/graphene hybrid was also prepared by a $\mathrm{HCOOH}$ reduction method. ${ }^{115}$ However, monometallic Pt is susceptible to deactivation or poisoning by some reaction intermediates especially CO molecules. Therefore, Pt-based alloys have been investigated as alternatives for improved catalyst stability. Alloying also results in the concomitant reduction of cost due to lowered noble metal content. Because of that, much effort has been directed towards the development of bimetallic (PtPd, ${ }^{\mathbf{1 1 6}, 117}$ PtAu, ${ }^{\mathbf{1 1 8 , 1 1 9}}$ PtRu, ${ }^{\mathbf{1 2 0}} \mathrm{PtFe},{ }^{\mathbf{1 2 1}} \mathrm{PtCo},{ }^{\mathbf{1 2 2}}$ PtNi, ${ }^{123} \mathrm{PtCu}^{\mathbf{1 2 4}} \mathrm{PtSn},{ }^{\mathbf{1 2 5}}$ etc.) and even ternary (PtPdAu $\left.{ }^{\mathbf{1 2 6}}\right)$ nanocatalysts. Typically, bimetallic nanodendrites with controllable size and numbers of Pt branches exhibit larger electrochemical active surface areas (Fig. 3f), thus leading to higher electrocatalytic activity compared to Pt/C electrocatalysts for MOR (Fig. 3g). ${ }^{127}$
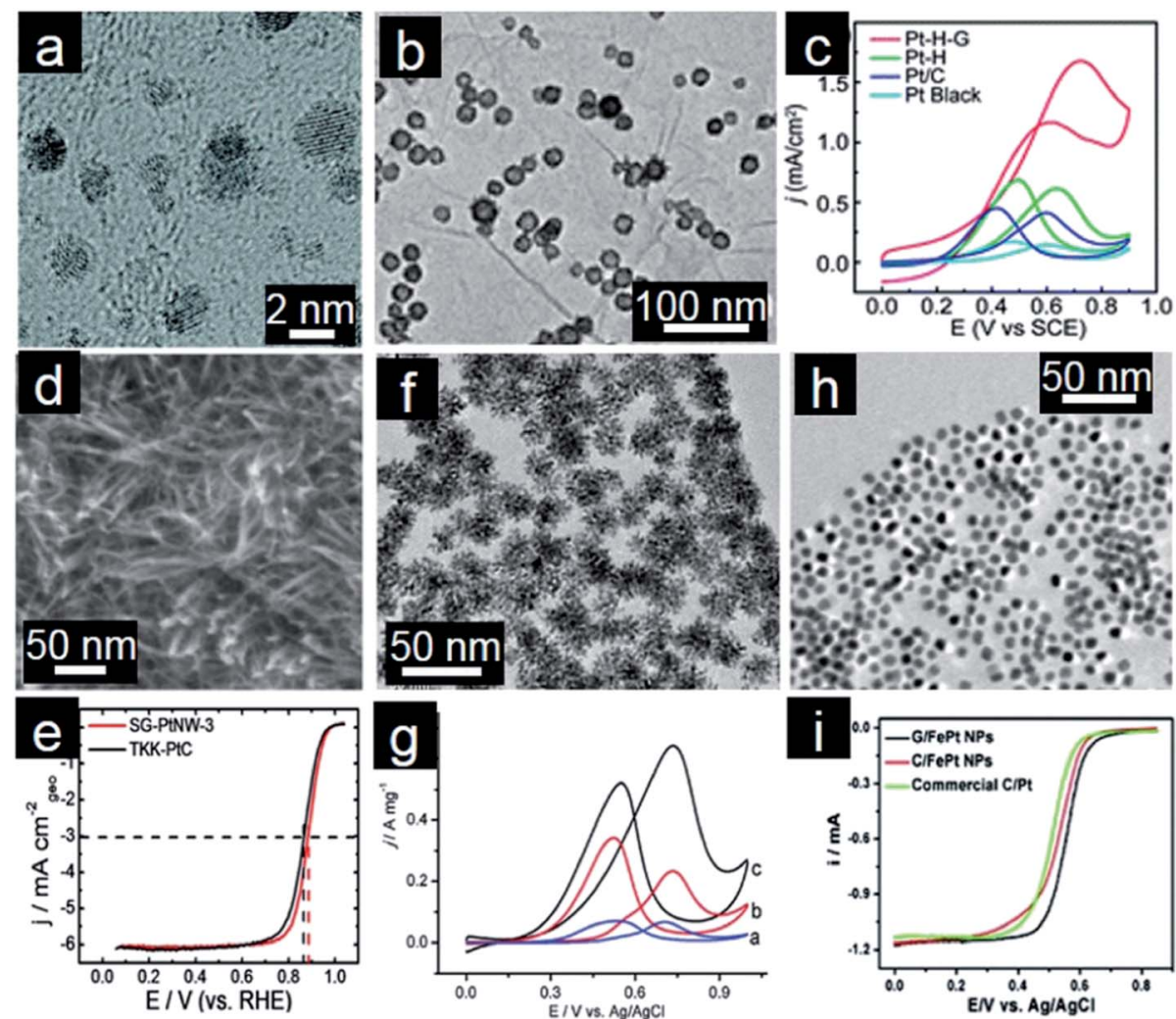

Fig. 3 (a) TEM image of Pt subnanoclusters/graphene. (Reprinted with permission from ref. 110. Copyright@ 2009, American Chemical Society.) (b) TEM image and (c) CVs for methanol oxidation of hollow Pt/graphene. (Reprinted with permission from ref. 112. Copyright@ 2012, Royal Society of Chemistry.) (d) TEM image, (e) ORR polarization curves in $\mathrm{O}_{2}$-saturated $0.1 \mathrm{M} \mathrm{HClO}_{4}$ solution $\left(10 \mathrm{mV} \mathrm{s}{ }^{-1} ; 1600 \mathrm{rpm}\right)$ of Pt nanowire arrays/S-doped graphene. (Reprinted with permission from ref. 114. Copyright@ $\odot$ 2013, Nature Publishing Group.) (f) TEM image, (g) CVs for methanol oxidation of 3D PtPd dendrites/graphene. (Reprinted with permission from ref. 127. Copyright@ 2010, American Chemical Society.) (h) TEM image and (i) RDE curves of FePt nanocubes assembled on graphene. (Reprinted with permission from ref. 137. Copyright@ 2012, American Chemical Society.) 
As discussed above, electrochemical performance of catalysts is strongly related to not only the size and composition but also to the shape and morphology of the nanoparticles. ${ }^{128}$ Considering the strong interaction between graphene supports and the formed noble metal nanoparticles, the supports will have a significant impact on the resultant nanoparticles with specific morphology due to different surface chemistries present. ${ }^{\mathbf{1 2 9 , 1 3 0}}$ To exert greater control over the particle formation process and thus reduce the influence of support surface chemistry, selfassembly techniques are employed to attach nanoparticles onto graphene. ${ }^{\mathbf{1 3 1 - 1 3 3}}$ This involves assembly of pre-prepared nanocrystals and graphene supports, thus the morphology and shape of nanocrystals can be efficiently controlled and improvement of electrochemical performance can be realized. ${ }^{134,135}$ Wang and coworkers reported self-assembly of mixed Pt and $\mathrm{Au}$ nanoparticles with controlled molar ratios and loadings onto PDDAfunctionalized graphene and these hybrid materials were used as highly effective electrocatalysts for formic acid oxidation. ${ }^{\mathbf{1 3 6}}$ Sun's group developed a facile solution phase self-assembly of FePt nanocubes on the graphene surface (Fig. $3 \mathrm{~h}$ ). ${ }^{\mathbf{1 3 7}}$ The desired size, composition and shape of FePt nanocrystals could be controlled during the preparation process. These graphene supported FePt nanocubes are more active and durable catalysts for ORR in $0.1 \mathrm{M} \mathrm{HClO}_{4}$ than unsupported nanoparticles or commercial Pt particles deposited on conventional carbon supports (Fig. 3i).

\subsection{Graphene supported other noble metals as electrocatalysts}

Pt and Pt-based alloys usually suffer from several disadvantages such as poisoning effects, corrosion by some electrolytes, and high costs. ${ }^{138,139}$ These problems might be in part mitigated in other noble metals and alloys. Further exploration of other noble metals and their alloys on graphene is thus of importance for both fundamental research and practical applications. ${ }^{\mathbf{1 4 0}}$

Pd nanocatalysts are more favorable for methanol and formic acid oxidation than Pt due to greater abundance and higher catalytic activity. ${ }^{\mathbf{1 4 1}} \mathrm{Xie}$ and coworkers prepared Pd/graphene by the redox reaction between $\mathrm{K}_{2} \mathrm{PdCl}_{4}$ and GO. Oxygenated functional groups present on the GO surface may take part in the formation of Pd/graphene. The clean surface of Pd/graphene, as a result of a surfactant-free synthesis procedure, alongside good dispersion on graphene, allows this nanocatalyst to show high electrocatalytic ability toward formic acid and ethanol oxidation (Fig. 4a). ${ }^{142}$ Using Ag/graphene as the support and the template, Chen and coworkers designed hollow PdAg nanorings decorated graphene nanosheets by a facile galvanic displacement reaction (Fig. 4b). More importantly, this PdAg/graphene nanohybrid exhibits not only high catalytic activity for the ORR but also remarkably high tolerance towards methanol crossover. ${ }^{143}$ Kim and coworkers designed a layer-by-layer (LBL) assembly to create $3 \mathrm{D}$ electrocatalytic thin films for methanol oxidation. ${ }^{\mathbf{1 4 4}}$ Graphene supported ultrafine $\mathrm{Au}$ nanoclusters without protecting agents exhibit surprisingly excellent electrocatalytic activity toward ORR and superior methanol tolerance (Fig. 4c and d). ${ }^{145}$ The authors concluded that this
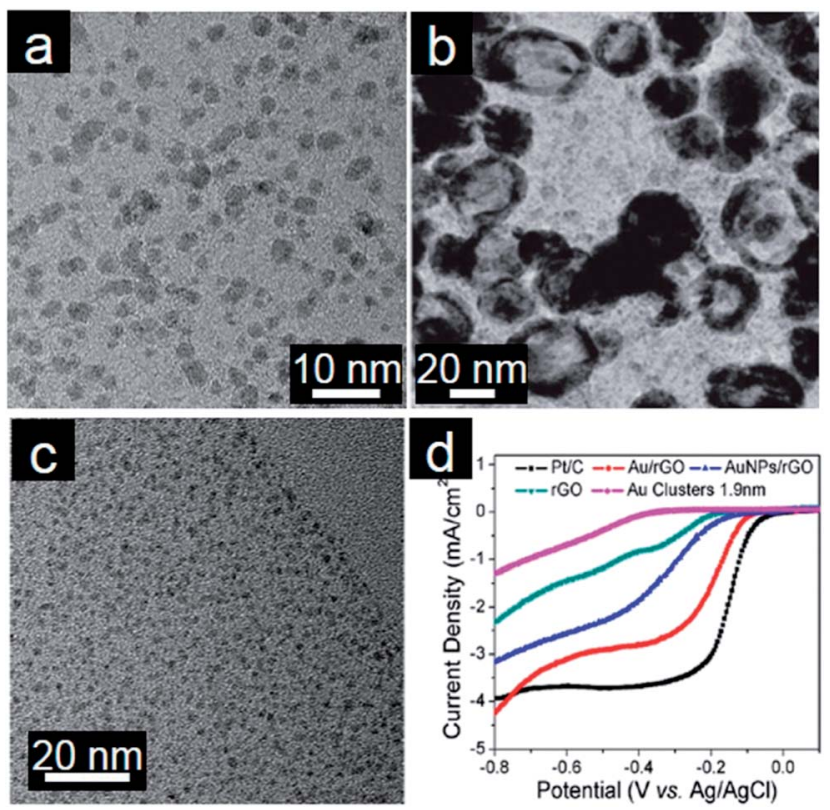

Fig. 4 (a) TEM image of Pd/graphene. (Reprinted with permission from ref. 142. Copyright(C) 2011, American Chemical Society.) (b) TEM image of PdAg nanorings/graphene. (Reprinted with permission from ref. 143. Copyright( 2013, WILEY-VCH.) (c) TEM image of assembled Au/graphene and (d) RDE curves of different electrocatalysts in $0.1 \mathrm{M} \mathrm{KOH}$ (50 mV s${ }^{-1} ; 1600 \mathrm{rpm}$ ). (Reprinted with permission from ref. 145. Copyright@ 2011, American Chemical Society.)

observation could be ascribed to small size of Au nanoparticles with a clean surface and the synergetic coupling effect between $\mathrm{Au}$ nanoclusters and graphene. Ag nanowires have been proven to be a good cathode catalyst in alkaline media. ${ }^{146}$ Thus, the combination of $\mathrm{Ag}$ nanowires and graphene also results in a better electrocatalyst than graphene or $\mathrm{Ag}$ nanowires because of the synergistic effect and creation of porous nanochannels. ${ }^{\mathbf{1 4 7}}$

\subsection{Noble metals attached on functionalized graphene}

As mentioned above, noble metal nanocrystals are deposited on graphene oxides with abundant functional groups. ${ }^{\mathbf{1 4 8}}$ These functional groups and defects present on the graphene surface act as active sites and nucleation sites for the formation of noble metals. They also strengthen the interaction between noble metal nanocrystals and graphene, thus enhancing the electrocatalytic activity and durability of the hybrid nanocatalysts. ${ }^{\mathbf{1 4 9}}$ Moreover, these oxygen-containing functional groups allow for good dispersion of graphene oxide in water and other organic solvents, which is a key factor for electrocatalytic application to prevent aggregation during catalyst preparation. ${ }^{150}$ However, reduced graphene oxides obtained from chemical and thermal reduction of graphene oxides inevitably possess defects and small defective graphene fragments. These defects include structural imperfections and chemical impurities and serve to disrupt the desirable electronic properties of reduced graphene oxide. ${ }^{151}$ Reduced graphene oxides are also easily oxidized and become unstable under harsh electrochemical conditions due to the corrosion of graphene. ${ }^{\mathbf{1 5 2}}$ Thus graphene with few defects 
is often required in the preparation of nanocatalysts. Graphene with high quality is obtained mostly by chemical vapor deposition (CVD) and other methods. ${ }^{153}$ However, graphene prepared by these methods possesses hydrophobic surfaces, which make it difficult to anchor metal nanoparticles directly. Therefore, surface modification is an efficient way to tune the surface chemistry of graphene, which in turn affects its dispersion ability and affinity for metal nanoparticles attachment. $^{88}$

Various methods have been developed to prepare functionalized graphene. ${ }^{\mathbf{1 5 4 , 1 5 5}}$ The resultant $\mathrm{Pt} /$ functionalized graphene catalysts typically exhibit improved catalytic performance and properties with respect to their specific applications compared to $\mathrm{Pt} /$ graphene. For instance, Wang and coworkers prepared $\mathrm{Pt} / \mathrm{N}$-doped graphene via a mild, plasma assisted approach which involves reduction of GO in ammonia plasma with subsequent simultaneous reduction of these $\mathrm{N}$-doped graphene sheets and $\mathrm{H}_{2} \mathrm{PtCl}_{6}$ in hydrogen plasma. ${ }^{156}$ This $\mathrm{Pt} / \mathrm{N}$-doped graphene hybrid exhibits high catalytic activity as a result of homogenous dispersion of 2-4 nm Pt nanoparticles onto Ndoped graphene. The presence of $\mathrm{N}$ - and O-containing functional groups is credited for enabling this strong interaction. Zheng and coworkers prepared Pt/graphene composites in an ionic liquid environment which is more oxytropic and less methanol-philic than the exterior aqueous solution. The resultant Pt/graphene hybrid exhibits both enhanced electrocatalytic activity and excellent methanol tolerance for ORR ${ }^{157}$ Graphene can also be functionalized by genomic double stranded DNA (gDNA) which serves two critical roles. First, gDNA bridges adjacent GO sheets via strong non-covalent interactions, thereby preventing aggregation. Second, purine bases in gDNA also serve as nucleation sites for $\mathrm{Pt}^{2+}$ owing to strong cation- $\pi$ interaction between $\mathrm{Pt}^{2+}$ and the purine ring. Pt/gDNA-GO composites exhibit significantly improved ORR performance compared to $\mathrm{Pt} / \mathrm{GO}$ and $\mathrm{Pt} / \mathrm{C}$ electrocatalysts. Again, the improved performance is likely due to the benefits of graphene functionalization with gDNA which helps in the efficient positioning of Pt nanoclusters onto GO. ${ }^{158}$

Graphene can also be functionalized with molecules or charged polyelectrolytes via $\pi-\pi$ stacking or hydrophobic interactions. Formation of these non-covalent bonds enables the intrinsic electronic and structural properties of graphene to be preserved. Non-covalent functionalization of graphene by PDDA, a linear cationic polyelectrolyte, is commonly reported to stabilize supports and metal nanoparticles. ${ }^{\mathbf{1 5 9 , 1 6 0}}$ Other non-covalent bonding agents such as cetyltrimethylammonium bromide (CTAB) are also used to functionalize graphene for electrocatalytic application. ${ }^{\mathbf{1 6 1}}$ Additionally, introduction of conductive polymers also provides a way to improve the conductivity of graphene supports and reduce interfacial resistance of hybrid catalysts. ${ }^{162} \mathrm{Li}$ and coworkers reported the preparation of the $\mathrm{Pt} /$ polyaniline (PANI) coated graphene composite which exhibits significantly enhanced electrocatalytic activity for methanol oxidation owing to the strong interaction between Pt and PANIgraphene. ${ }^{163}$ As the conducting bridge, polypyrrole (PPy) coating can also increase the hydrophilicity of pristine graphene nanosheets which are hydrophobic. These Pt/graphene-polymer nanocomposites have a higher surface area with more active sites leading to better electrocatalytic performance when compared to Pt/graphene. ${ }^{\mathbf{1 6 4 , 1 6 5}}$

\subsection{Noble metals supported on graphene nanostructures}

The prominent effects of graphene supports on the activity and stability of electrocatalysts have been demonstrated. ${ }^{166,167}$ Aggregation of graphene sheets can also be resolved by using GQDs, a newly developed nanosized graphene. ${ }^{168,169}$ Abundant structural defects of GQDs can manipulate the dissociative adsorption of oxygen and binding of reaction intermediates $\mathrm{O}^{*}$ and $\mathrm{HO}^{*}$ on Pt surfaces. ${ }^{\mathbf{1 7 0}}$ Recently, the covalent interaction between Pd particles and GQDs was proven by infrared spectroscopy. ${ }^{\mathbf{1 7 1}}$ Generally, an electrode with a proper and welldesigned nanoarchitecture can achieve excellent performance. ${ }^{172,173}$ On the other hand, the planar stacking of $2 \mathrm{D}$ graphene results in the formation of irreversible agglomerates which in turn leads to a drastic loss of electroactivity during the electrocatalyst assembly. ${ }^{174} 3 \mathrm{D}$ porous graphene structures have also been designed and could lead to significantly enhanced electrochemical performance. ${ }^{175}$ As a consequence, 3D graphene frameworks are desirable for high catalyst loading to facilitate the mass transfer and maximize accessibility of the catalyst surface. ${ }^{176-180}$ Dong and coworkers reported the assembly of Pt nanoparticles on graphene to form 3D nanocomposites as ORR electrocatalysts. The electrocatalytic activity of resultant Pt/graphene nanocomposites can be tailored by simply changing the layering processes. ${ }^{181}$ Dai and coworkers prepared shape-defined ternary $\mathrm{Pt} / \mathrm{PdCu}$ nanoboxes anchored onto a 3D graphene framework by a solvothermal process (Fig. 5a). As a new catalyst system for ethanol electrooxidation, the ternary $\mathrm{Pt} / \mathrm{PdCu}$ nanoboxes/graphene electrocatalyst demonstrates significantly higher electrochemical performance when normalized to the total mass loading of hollow structures of active particles. Again it is attributed to the synergetic effect among components as well as the 3D interconnected graphene framework (Fig. 5b). ${ }^{\mathbf{1 8 2}}$

Re-stacking of $2 \mathrm{D}$ individual graphene sheets can be partially overcome by intercalating nanoparticles between the graphene layers. ${ }^{\mathbf{1 8 3}}$ Moreover, migration of noble metal nanoparticles and CO poisoning also limit the efficiency of electrocatalysts. ${ }^{\mathbf{1 8 4}}$ To enhance the electrochemical performance in terms of activity and durability, graphene coupled with metal oxides have proved to be effective supports. ${ }^{\mathbf{1 8 5 - 1 9 0}}$ For instance, Liu and coworkers reported the in situ formation of ITO-Pt-graphene triple junctions that enhances the interaction and contact among the components for the improved electrochemical activity and stability (Fig. 5c and d). ${ }^{191} \mathrm{TiO}_{2}$ nanosheets are introduced into Pt-graphene catalysts to form sandwich structures which enable maximum interaction among $\mathrm{TiO}_{2}$, Pt and graphene (Fig. 5e), hence improving the electrocatalytic performance (Fig. 5f). ${ }^{192}$ Incorporation of $\mathrm{SnO}_{2}, \mathrm{CeO}_{2}$ and $\mathrm{MnO}_{2}$ into graphene-based hybrid electrocatalysts has also been investigated. ${ }^{187,193,194}$ It is important to note that simultaneous incorporation of different components onto graphene with homogenous distribution will play a critical role on the eventual electrochemical performance of the catalyst. Ideally, components should be incorporated with 

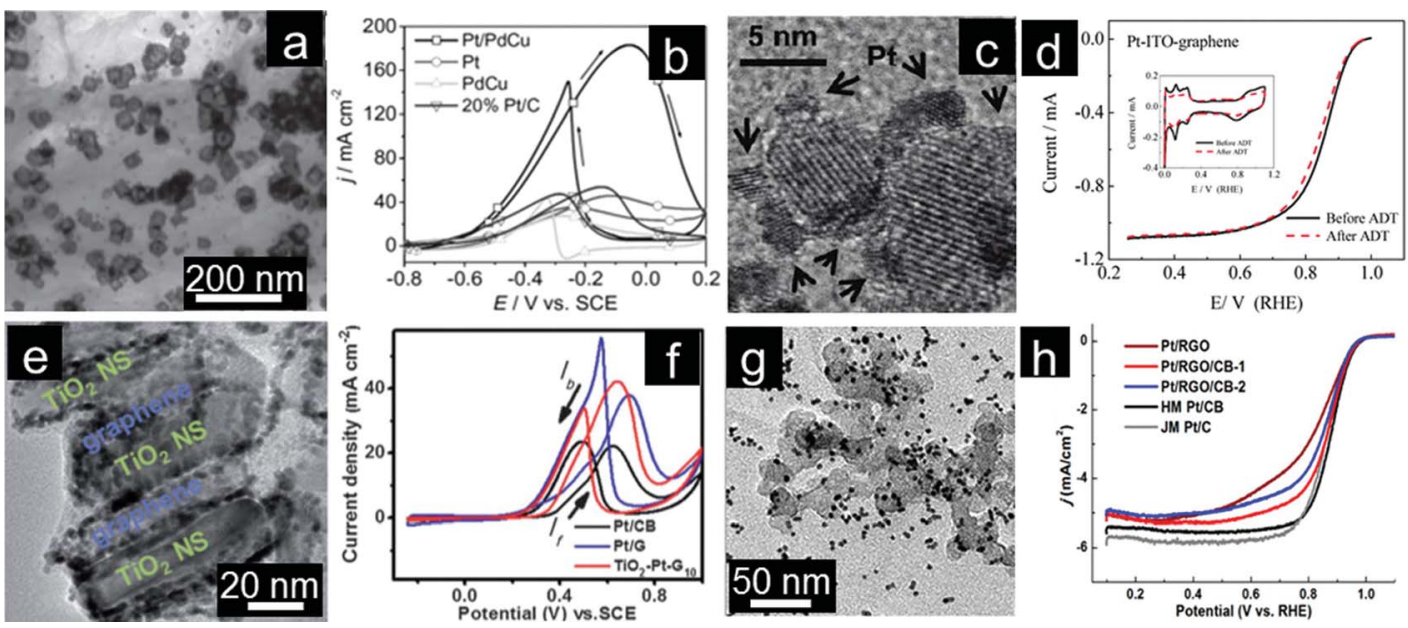

Fig. 5 (a) TEM image and (b) CVs for ethanol oxidation of Pt/PdCu nanocubes assembled on the 3D graphene framework. (Reprinted with permission from ref. 182. Copyright@ 2012, WILEY-VCH.) (c) TEM image and (d) RDE curves of the ITO-Pt-graphene electrocatalyst. Inset of (d) shows stability tests. (Reprinted with permission from ref. 191. Copyright $\odot$ 2011, American Chemical Society.) (e) TEM image and (f) CVs for methanol oxidation of sandwich structured $\mathrm{TiO}_{2}-\mathrm{Pt}$-graphene. (Reprinted with permission from ref. 192. Copyright@ 2012, Royal Society of Chemistry.) (g) TEM image and (h) RDE curves of different Pt/graphene-carbon black composites for electrocatalysts. (Reprinted with permission from ref. 242. Copyright@ 2012, American Chemical Society.)

maximum interaction with each other to generate synergetic effects. Density functional theory (DFT) study has proved that the enhanced interaction of three components present is responsible for the enhanced electrochemical performance. ${ }^{191}$

Re-stacking of individual graphene sheets can be effectively inhibited by introducing carbon materials to form 3D hierarchical structures. ${ }^{195-199}$ For example, Huang and coworkers reported an approach to design a highly active and durable ORR catalyst by loading Pt nanoparticles on graphene nanosheets that are supported on high surface area carbon black (CB) (Fig. 5g). Placing CB nanoparticles between the Pt/graphene sheets not only enhances the catalytic activity but also dramatically improves the durability of the catalyst (Fig. 5h). ${ }^{200}$ The authors concluded that the unique $2 \mathrm{D}$ structure of graphene functions as a barrier to prevent leaching of Pt into the electrolyte and CB nanoparticles within the vicinity act as active sites to recapture/renucleate the dissolved Pt species.

\section{Non-metal/graphene hybrid nanostructures as electrocatalysts}

Driven by the economical consideration, electrocatalysts based on graphene and non-metals have attracted great interest in the past few years. ${ }^{201,202}$ Incorporation of inorganic nanocrystals onto graphene would reduce dissolution, sintering and aggregation of nanoparticles during the electrochemical operation. At the same time, the low intrinsic electric conductivity of inorganic composites is also significantly improved. ${ }^{203}$ Tremendous progress has been made in exploring these non-metal/graphene electrocatalysts. ${ }^{204,205}$ These novel nanostructures exhibit superior electrocatalytic activity as well as selectivity and durability, which can act as promising electrodes for electrochemical reactions. ${ }^{206}$

\subsection{Metal oxides/graphene hybrids as electrocatalysts}

Transition metal ( $\mathrm{Co}, \mathrm{Mn}, \mathrm{Fe}, \mathrm{Cu}$, etc.) oxides with mixed valences are reportedly able to serve as donor-acceptor chemisorption sites for the reversible adsorption of oxygen and hence have the potential to replace noble metal based electrocatalysts. ${ }^{207,208}$ However, metal oxides, which are poorly conductive, frequently suffer from dissolution and aggregation during the electrochemical reaction. ${ }^{208-210}$ A suitable strategy for overcoming the abovementioned problems is to anchor these transition metal oxides onto graphene. Graphene-based transition metal oxide electrocatalysts thus show remarkable improvements in electrochemical activity, durability and dispersion., ${ }^{4,15}$ Dai and coworkers deposited $\mathrm{Co}_{3} \mathrm{O}_{4}$ nanoparticles on a graphene support and investigated their electrocatalytic activity. ${ }^{211}$ Using $\mathrm{N}$-doped graphene leads to more uniform distribution of $\mathrm{Co}_{3} \mathrm{O}_{4}$ nanoparticles with smaller sizes (Fig. 6a). The resultant $\mathrm{Co}_{3} \mathrm{O}_{4} /$ graphene hybrid exhibits higher ORR activity than either $\mathrm{Co}_{3} \mathrm{O}_{4}$ or graphene alone and favors a 4 e process (Fig. 6b). Moreover, the ORR activity decreases monotonically when the Co loading on graphene decreases from $20 \%$ to $3 \%$. Importantly, the hybrid is also a highly active OER catalyst for water oxidation (Fig. 6c). The less oxidized $\mathrm{CoO}$ nanoparticles possibly make the electrocatalyst more electron rich, which might be beneficial for enhanced ORR activity. ${ }^{212,213}$

Metal oxide nanoparticles are typically loaded on graphene with little control in size and morphology. ${ }^{128}$ This makes tuning the interaction between nanoparticles and graphene difficult. ${ }^{214}$ To address this issue, Sun and coworkers assembled presynthesized monodisperse $\mathrm{Co} / \mathrm{CoO}$ core/shell nanoparticles on the graphene surface (Fig. $6 \mathrm{~d}$ ). ${ }^{215}$ The Co core size and thickness of the $\mathrm{CoO}$ shell in $\mathrm{Co} / \mathrm{CoO}$ core/shell nanoparticles can be tuned by controlling the oxidation conditions. They also demonstrated the importance of $\mathrm{Co} / \mathrm{CoO}$ dimension and 

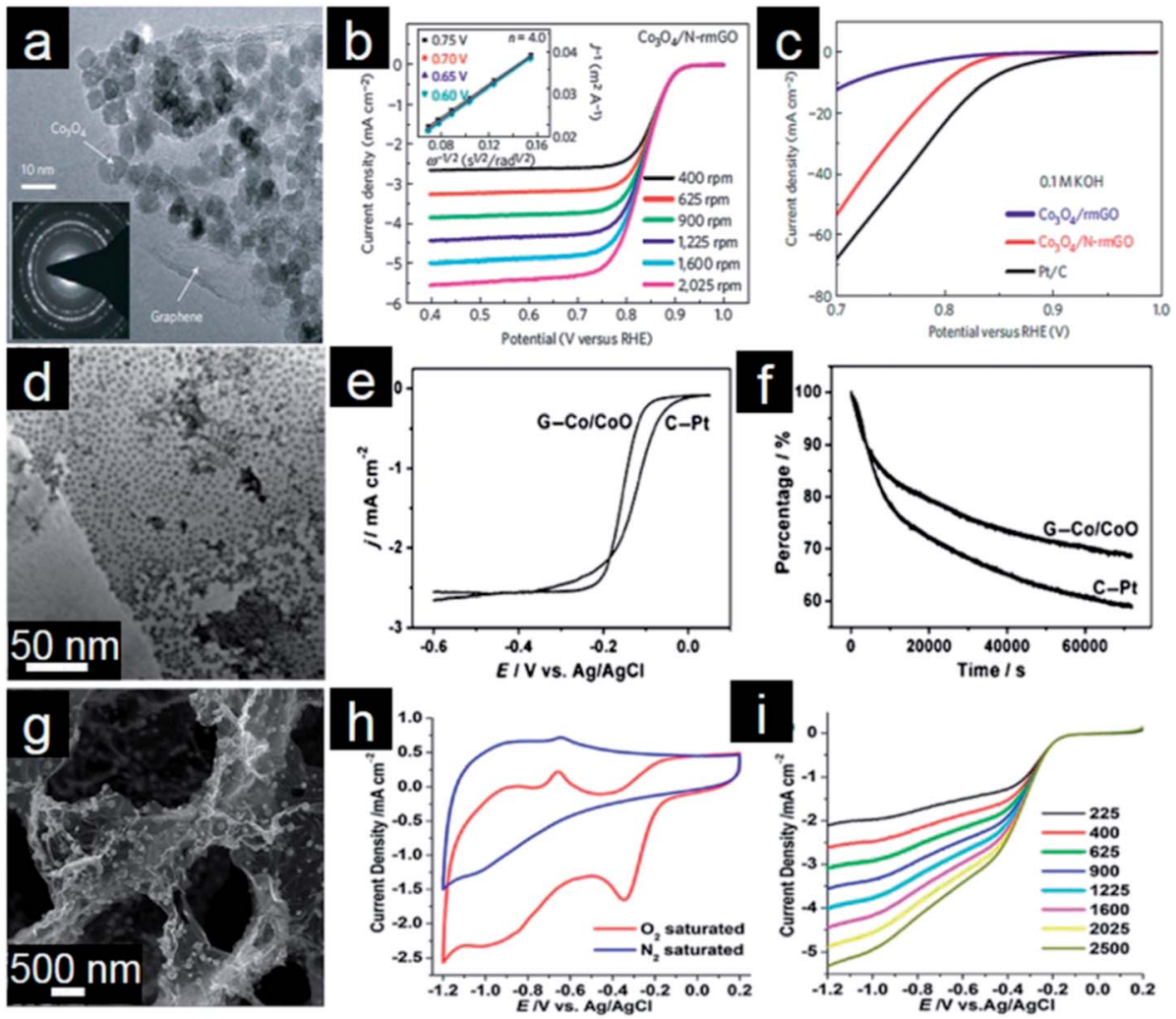

Fig. 6 (a) TEM image with an inset showing a selected-area electron diffraction (SAED) pattern of $\mathrm{CO}_{3} \mathrm{O}_{4} / g r a p h e n e$. (b) RDE curves in $0.1 \mathrm{M}$ KOH with different rotation rates; inset of (b) shows corresponding Koutecky-Levich (K-L) plots. (c) RDE curves of different electrocatalysts in $0.1 \mathrm{M}$ $\mathrm{KOH}$. (Reprinted with permission from ref. 211. Copyright $\odot$ 2011, Nature Publishing Group.) (d) TEM of Co/CoO/graphene composites, (e) RDE curves of $\mathrm{Pt} / \mathrm{C}$ and $\mathrm{Co} / \mathrm{CoO} /$ graphene $\left(10 \mathrm{mV} \mathrm{s}^{-1} ; 400 \mathrm{rpm}\right)$ and (f) chronoamperometric responses at $-0.3 \mathrm{~V}$ in $\mathrm{O}_{2}$ saturated $0.1 \mathrm{M} \mathrm{KOH}$ solution. (Reprinted with permission from ref. 215. Copyright@ 2012, WILEY-VCH.) (g) SEM image, (h) CVs and (i) RDE curves of Fe $3 \mathrm{O}_{4} / 3 \mathrm{D}$ N-doped graphene aerogel composites. (Reprinted with permission from ref. 230. Copyright@ 2012, American Chemical Society.)

graphene as a support in tuning electrocatalysts for efficient ORR with a selective $4 \mathrm{e}$ process (Fig. 6e). The optimized $\mathrm{Co} /$ CoO-graphene electrocatalyst shows comparative activity and better stability than the commercial $\mathrm{Pt} / \mathrm{C}$ catalyst and thus might serve as a promising alternative to $\mathrm{Pt} / \mathrm{C}$ catalysts for the ORR in alkaline solutions (Fig. 6f). It was further shown that the ORR activity of cobalt oxide-graphene hybrid electrocatalysts is dramatically improved by increasing the Co content and coupling with $\mathrm{N}$-doped graphene. ${ }^{216}$ Cobalt oxides/graphene hybrids were also used as the ORR catalysts in $\mathrm{Li}_{-} \mathrm{O}_{2}$ batteries. A bi-functional catalyst composed of $\mathrm{Co}_{3} \mathrm{O}_{4}$ nanofibers immobilized on both sides of graphene sheets was proposed for the oxygen electrode. ${ }^{217}$ The excellent electrochemical performance could mainly be attributed to the structure and interaction between $\mathrm{Co}_{3} \mathrm{O}_{4}$ nanofibers and graphene for the facile electron transport and fast $\mathrm{O}_{2}$ diffusion through the ultrathin graphene layer and porous $\mathrm{Co}_{3} \mathrm{O}_{4}$ nanofiber networks.

Manganese oxides supported on graphene have also been employed as active, stable and low-cost cathode electrocatalysts for fuel cells and Li-air batteries. ${ }^{218-220}$ The results show that the catalytic performance of metal oxides is associated with morphology, size and oxide-graphene coupling.. ${ }^{221,222}$ For example, Qiao and coworkers reported a mesoporous architecture of $\mathrm{Mn}_{3} \mathrm{O}_{4}$ /graphene hybrids which demonstrates a competitive ORR activity and excellent durability with high selectivity. ${ }^{223} \mathrm{Kim}$ and coworkers also found that the oxygen reduction pathway of these composites is tunable with the relative amount of $\mathrm{Mn}_{3} \mathrm{O}_{4}$ supported on graphene sheets. For example, the ORR mechanism of the system with a lower content $(19.2 \%)$ of $\mathrm{Mn}_{3} \mathrm{O}_{4}$ nanoparticle is similar to that of the $\mathrm{Pt} / \mathrm{C}$ electrode with a $4 \mathrm{e}$ transfer, whereas the hybrid with a higher $\mathrm{Mn}_{3} \mathrm{O}_{4}$ content $(52.5 \%)$ undergoes a classical $2 \mathrm{e}$ process. ${ }^{224}$ Other graphene supported metal oxides such as $\mathrm{Fe}_{3} \mathrm{O}_{4}{ }^{225}$ $\mathrm{Fe}_{2} \mathrm{O}_{3}{ }^{226} \mathrm{Cu}_{2} \mathrm{O},{ }^{227,228}$ and $\mathrm{Ru}_{2} \mathrm{O}^{229}$ were also investigated as electrocatalysts for ORR in fuel cells and $\mathrm{Li}$-air batteries. Feng and Mullen demonstrated the controllable assembly of $\mathrm{Fe}_{3} \mathrm{O}_{4}$ nanoparticles on 3D N-doped graphene aerogels. ${ }^{230}$ As shown in Fig. $6 \mathrm{~g}$, the graphene hybrid shows an interconnected macroporous framework with uniform deposition of $\mathrm{Fe}_{3} \mathrm{O}_{4}$ nanoparticles. Due to unique structural features, the resulting $\mathrm{Fe}_{3} \mathrm{O}_{4} /$ $\mathrm{N}$-graphene aerogels show excellent electrocatalytic activity for the ORR in alkaline electrolytes, including a higher current density, lower ring current, lower $\mathrm{H}_{2} \mathrm{O}_{2}$ yield, higher electron transfer number, and better durability (Fig. $6 \mathrm{~h}$ and i).

Substitution of Co by $\mathrm{Mn}$ and $\mathrm{Ni}$ in the spinel lattice can further improve electrocatalytic performance of the resulting $\mathrm{MnCo}_{2} \mathrm{O}_{4}$-graphene and $\mathrm{NiCo}_{2} \mathrm{O}_{4}$-graphene hybrid catalysts. ${ }^{231}$ Dai and coworkers reported $\mathrm{MnCo}_{2} \mathrm{O}_{4} / \mathrm{N}$-doped graphene 
hybrids as highly efficient ORR electrocatalysts in alkaline conditions (Fig. 7a). Mn substitution increases activity of catalytic sites of the hybrid materials, further boosting the ORR activity compared with the pure $\mathrm{Co}_{3} \mathrm{O}_{4} /$ graphene hybrid (Fig. 7b). ${ }^{232}$ The $\mathrm{MnCo}_{2} \mathrm{O}_{4}$-graphene hybrid material was also employed as the cathode catalyst for $\mathrm{Li}-\mathrm{O}_{2}$ battery in a nonaqueous electrolyte. It is suggested that the excellent catalytic activity originates mainly from the strong coupling effect between $\mathrm{MnCo}_{2} \mathrm{O}_{4}$ nanoparticles and $\mathrm{N}$-doped graphene. The high catalytic activity of the $\mathrm{MnCo}_{2} \mathrm{O}_{4}$-graphene hybrid for the ORR could facilitate the discharging reaction in $\mathrm{Li}-\mathrm{O}_{2}$ cells. ${ }^{233}$ Moreover, incorporation of $\mathrm{Ni}$ atoms into the octahedral sites of the spinel lattice not only creates new active sites but also significantly improve the electrical conductivity. ${ }^{234}$ Therefore, the $\mathrm{NiCo}_{2} \mathrm{O}_{4}$ nanoplates-graphene hybrid can be used as a highly active bi-functional catalyst for ORR and OER. ${ }^{235}$ There are also some reports on preparation of graphene- $\mathrm{Co}(\mathrm{OH})_{2}$ composites as cathode electrocatalysts for ORR. ${ }^{236,237}$ These nanocomposites show good catalytic activity, in which graphene decreases the reaction overpotential and $\mathrm{Co}(\mathrm{OH})_{2}$ catalyzes the disproportionation of intermediates.

\subsection{Metal chalcogenides/graphene hybrids as electrocatalysts}

The metal oxide/graphene electrocatalysts discussed above are mainly active in a basic environment. However, many electrochemical systems, such as proton exchange membrane fuel cells, also involve an acidic environment; thus it is necessary to explore other non-metal electrocatalysts which exhibit high activity and stability under acidic conditions. ${ }^{238,239}$ Sulfides of non-precious transition metals have attracted intensive interest owing to their noble metal-like catalytic properties. ${ }^{240}$ Cobalt sulfides have shown great potential as electrocatalysts because they are thermally and chemically more stable than metal oxides, especially in acidic media. Therefore, cobalt sulfides are regarded as one of the most active ORR electrocatalysts in both acidic and basic electrolytes. ${ }^{241-243}$ However, low conductivity of these sulfides and the dominance of the 2e pathway limit their electrochemical performance for ORR. ${ }^{4}$ To overcome these limitations, Dai and coworkers employed graphene as a conducting support for controlling the size of catalytically active
$\mathrm{Co}_{1-x} \mathrm{~S}$ particles (Fig. 8a). ${ }^{244}$ The designed $\mathrm{Co}_{1-x} \mathrm{~S} /$ graphene hybrid shows improved electrocatalytic activity and stability compared to $\mathrm{Co}_{1-x} \mathrm{~S}$ particles, and it undergoes the $4 \mathrm{e}$ ORR process in both acidic and alkaline media (Fig. 8b and c). Therefore, incorporation of $\mathrm{Co}_{1-x} \mathrm{~S}$ particles onto graphene affords an efficient way to render electrochemical active sites for unprecedented ORR catalytic performance. Subsequently, Hou and coworkers investigated the multi-functionality of $\mathrm{Co}_{3} \mathrm{~S}_{4} /$ graphene composites to enhance the thermal stability and conductivity. ${ }^{245}$ The resultant cobalt sulfide/graphene composites similarly exhibit high durability in acidic and basic media and also follow the $4 \mathrm{e}$ process. Yu and coworkers reported that the electrochemical ORR activity of ZnSe could be enhanced by coupling with $\mathrm{N}$-doped graphene. ${ }^{246} \mathrm{With}$ the further Ni doping into cobalt sulfides, the designed $\mathrm{NiCo}_{2} \mathrm{~S}_{4} /$ graphene composites manifest not only higher ORR activity but also much better durability toward OER than the CoS/graphene system (Fig. 8df). ${ }^{247}$ Different from its widely accepted role as electron reservoir, a novel role of graphene for ORR as a peroxide cleaner has been proposed in these sulfides/graphene composites. ${ }^{248}$

The hydrogen evolution reaction (HER, $2 \mathrm{H}^{+}+2 \mathrm{e} \rightarrow \mathrm{H}_{2}$ ), which involves proton reduction and concomitant hydrogen evolution, is an important reaction involved in water splitting. Efficient electrocatalysts for HER are required to reduce overpotential and enable HER to be carried out with high energy efficiency. ${ }^{249}$ Under these considerations, Pt-based noble metals are considered as the most effective HER electrocatalysts. ${ }^{250}$ However, the search for new HER electrocatalysts with low cost and high activity has attracted a great deal of interest due to their important role in clean energy generation. ${ }^{240} \mathrm{MoS}_{2}$ nanoparticles demonstrate good potential as an inexpensive alternative to Pt for HER. ${ }^{251,252}$ The catalytic activity of $\mathrm{MoS}_{2}$ is mainly localized to some small fraction of surface sites, whereas the bulk part is relatively inert. ${ }^{253}$ Therefore, increasing the amount of active sites for $\mathrm{MoS}_{2}$-based electrocatalysts is necessary to enable greater activity for HER. Inspired by the great enhancement observed by coupling inorganic nanocrystals with graphene, Dai and coworkers introduced $\mathrm{MoS}_{2}$ nanoparticles on graphene (Fig. 9a). ${ }^{254}$ Strong chemical and electronic coupling between $\mathrm{MoS}_{2}$ and graphene allows for good dispersion of $\mathrm{MoS}_{2}$ nanoparticles and rapid electron transport from the less
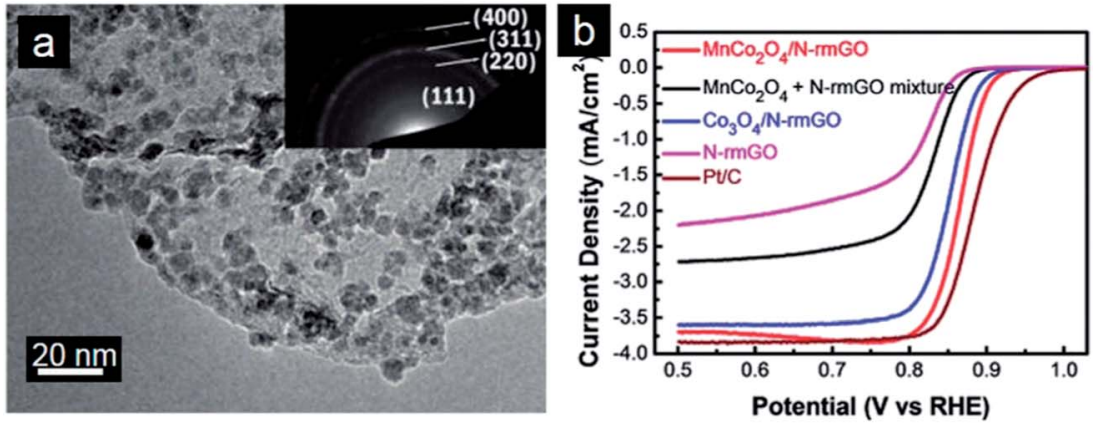

Fig. 7 (a) TEM image of $\mathrm{MnCO}_{2} \mathrm{O}_{4} / \mathrm{N}$-doped graphene hybrids with the inset showing the SAED pattern and (b) RDE curves of different electrocatalysts in $\mathrm{O}_{2}$-saturated $1 \mathrm{M} \mathrm{KOH}\left(5 \mathrm{mV} \mathrm{s}^{-1} ; 1600 \mathrm{rpm}\right)$. (Reprinted with permission from ref. 232. Copyright@ 2012, American Chemical Society.) 

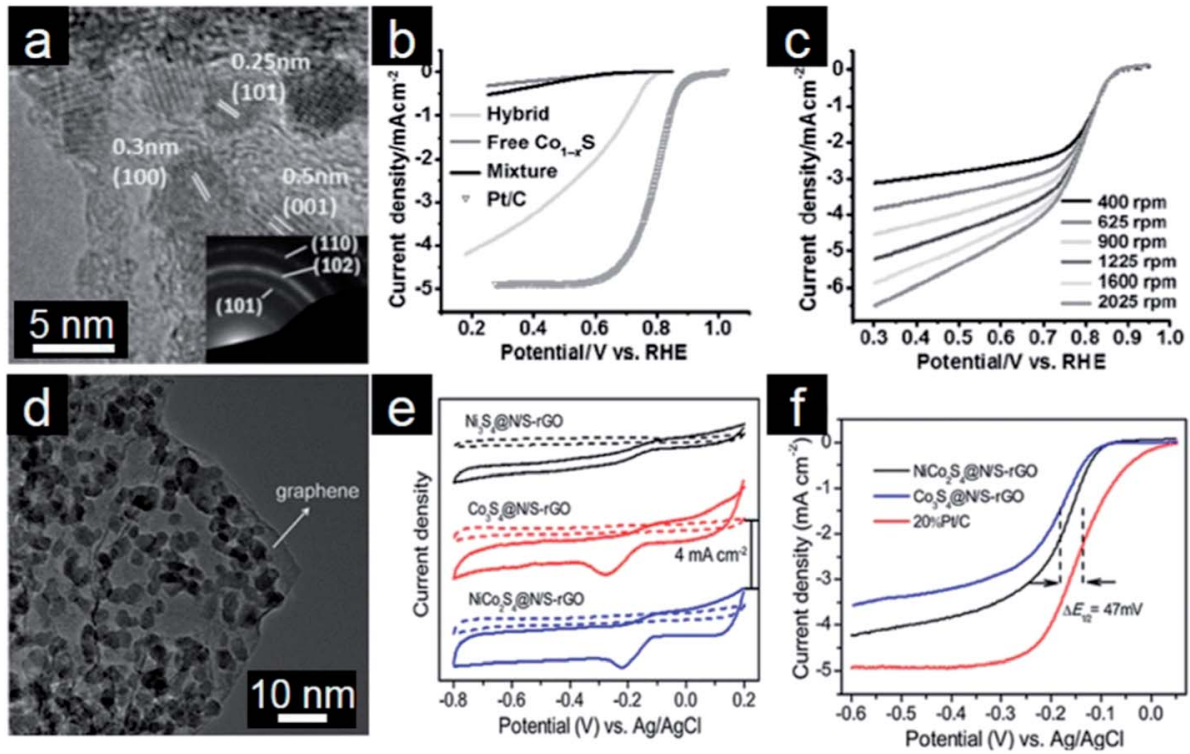

Fig. 8 (a) TEM image of the $\mathrm{CO}_{1-x} \mathrm{~S} / \mathrm{rGO}$ hybrid with the inset showing the SAED pattern. (b) RDE curves of different catalysts in $\mathrm{O}_{2}$-saturated $0.5 \mathrm{M} \mathrm{H}_{2} \mathrm{SO}_{4}\left(5 \mathrm{mV} \mathrm{s}^{-1} ; 1600 \mathrm{rpm}\right)$. (c) RDE curves of the $\mathrm{Co}_{1-x} \mathrm{~S} / \mathrm{rGO}$ hybrid in $\mathrm{O}_{2}$ saturated $0.1 \mathrm{M} \mathrm{KOH}$ solution with a scanning rate of $5 \mathrm{mV} \mathrm{s} \mathrm{s}^{-1}$. (Reprinted with permission from ref. 244. CopyrightC 2011, WILEY-VCH.) (d) TEM image of $\mathrm{NiCO}_{2} \mathrm{~S}_{4} /$ graphene, (e) CVs and (d) RDE curves of different cobalt sulfides/graphene hybrids in $\mathrm{O}_{2}$-saturated $0.1 \mathrm{M} \mathrm{KOH}$ solution $\left(5 \mathrm{mV} \mathrm{s}^{-1} ; 1600 \mathrm{rpm}\right.$ ). (Reprinted with permission from ref. 247 . Copyright@ 2013, American Chemical Society.)

conductive $\mathrm{MoS}_{2}$ nanoparticles to the electrode. The $\mathrm{MoS}_{2} /$ graphene hybrid catalyst exhibits smaller overpotential of $\sim 0.1 \mathrm{~V}$ and much improved HER current density (Fig. 9b). The subsequent Tafel analysis showed a Tafel slope of $\sim 41 \mathrm{mV}$ per decade (Fig. 9c). The large amount of exposed edges (presumably active sites) from these small $\mathrm{MoS}_{2}$ nanoparticles uniformly dispersed on graphene leads to significantly enhanced activity. ${ }^{255}$ Furthermore, the interconnected conductive network with porous nanostructure (from 3D graphene framework) was anticipated to enhance the activity of embedded $\mathrm{MoS}_{2}$ nanocatalysts (Fig. 9d). ${ }^{256}$ Thanks to its 3D architectural characteristics, this $\mathrm{MoS}_{2}$ /graphene composite shows high activity for HER with a Tafel slope of $\sim 42 \mathrm{mV}$ per decade and a small overpotential of $\sim 0.1 \mathrm{~V}$ (Fig. 9e and f). 3D graphene based electrocatalysts are further developed by growing $\mathrm{MoS}_{x}$ onto graphene-protected 3D Ni foam to provide robust protection and efficiently increase their stability in acidic media. The 3D porous structure also effectively increases the $\operatorname{MoS}_{x}$ catalyst loading, leading to enhanced electrocatalytic HER efficiency. The hydrogen evolution rate is as high as $302 \mathrm{~mL} \mathrm{~g}^{-1}$ $\mathrm{cm}^{-2} \mathrm{~h}^{-1}$ at an overpotential of $0.2 \mathrm{~V}^{257}$

2D $\mathrm{MoS}_{2}$ nanosheets with rich exposed edges demonstrate improved activity for HER. ${ }^{258}$ However, curling of sheets and aggregation to form tubes or fullerene-like structures will lower the activity of $\mathrm{MoS}_{2}$ nanosheets. ${ }^{259}$ As such, GO has been employed as a highly selective substrate for the synthesis of layered $\mathrm{MoS}_{2}$ hybrid electrocatalysts. ${ }^{260,261}$ However, both GO and $\mathrm{MoS}_{2}$ tend to re-stack and aggregate. Thus, the introduction of other conductive and active nanoparticles has been used as a method to improve the $\mathrm{H}_{2}$ production performance. ${ }^{262}$ Wang and coworkers introduced WC nanoparticles as the spacers to create void for the growth of $\mathrm{MoS}_{2}$ nanosheets (Fig. 9g). The as- prepared $\mathrm{MoS}_{2} / \mathrm{WC} /$ graphene hybrid material displays high HER activity with a Tafel slope of $\sim 41 \mathrm{mV}$ per decade and a small overpotential of $\sim 0.15 \mathrm{~V}$ (Fig. $9 \mathrm{~h}$ and i). Synergistic effects among the components and enhanced electron transfer are suggested responsible for the enhanced electrochemical performance. ${ }^{263}$

\subsection{Nitrides/graphene hybrids as electrocatalysts}

As previously mentioned, pyridinic and graphitic $\mathrm{N}$ atoms are generally accepted as the active sites in graphene-based electrocatalysts. However, the limited $\mathrm{N}$ doping content $(2-5 \%)$ and leaching of $\mathrm{N}$ active sites on graphene composites result in low and unstable electrocatalytic activity. Therefore, carbon or transition metal nitrides with stable structures and high $\mathrm{N}$ content such as those containing pyridinic and graphitic $\mathrm{N}$ moieties may serve as potential non-noble metal electrocatalysts. ${ }^{264-266}$ However, the low conductivity of pure nitrides will strongly restrict electron transfer during electrochemical reactions and also reduce the electrocatalytic activity. ${ }^{267}$ Therefore, researchers focused on incorporation of conductive components such as graphene nanosheets into the nitride matrix to improve the electron transfer efficiency in the resulting hybrids. ${ }^{268,269}$ Considering the excellent conductivity of graphene and layered structures of both graphene and carbon nitride nanosheets, Feng and coworkers developed a nanocasting technique to fabricate graphene-based carbon nitride nanosheets (Fig. 10a). ${ }^{265}$ The resulting composites possess beneficial features such as high $\mathrm{N}$ content, small thickness, high surface area, large aspect ratio as well as enhanced electrical conductivity. Such features are favorable for ease of oxygen access to the catalyst surface and facilitate rapid transfer 

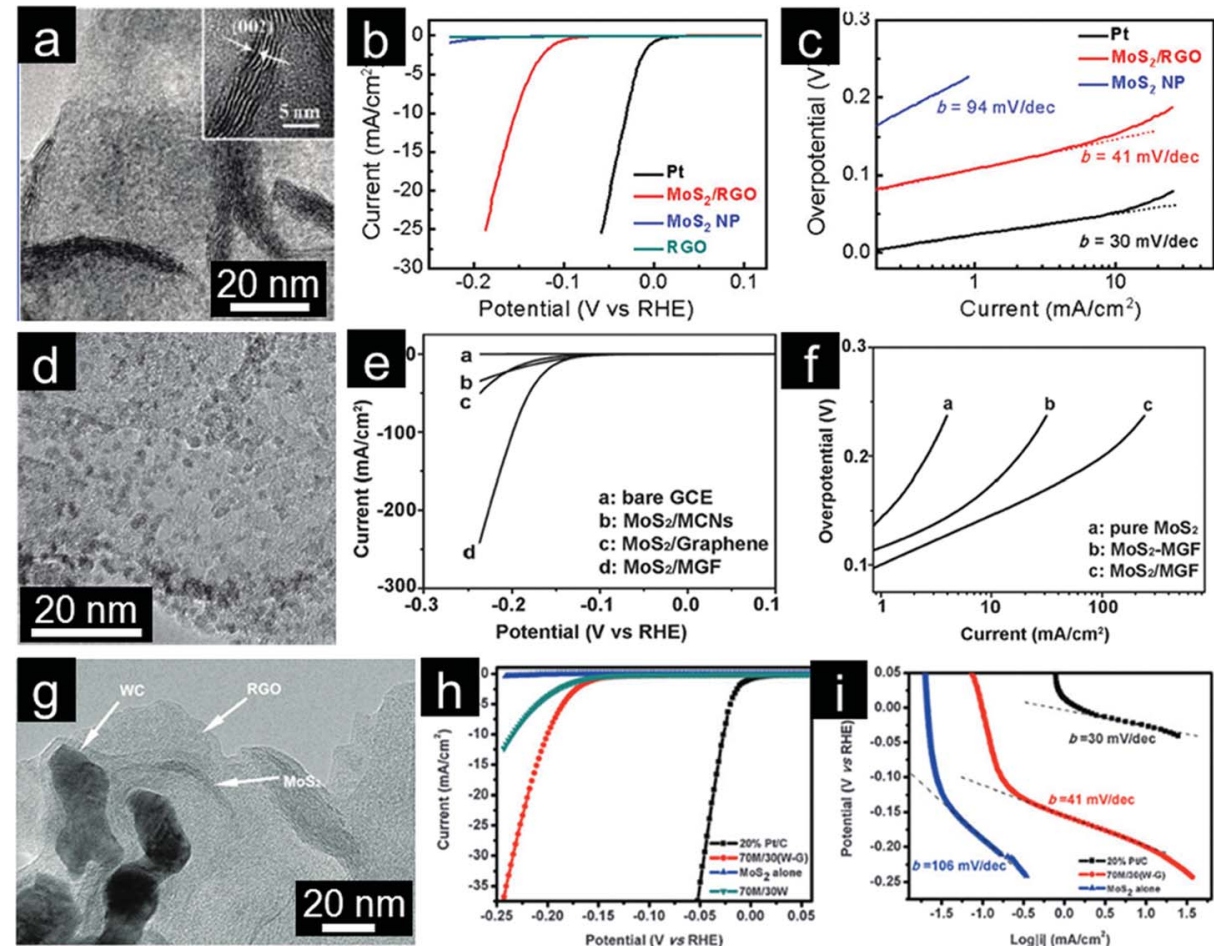

Fig. 9 (a) TEM image with the inset showing the folded edge of the $\mathrm{MOS}_{2} / \mathrm{rGO}$ hybrid, (b) polarization curves, and (c) corresponding Tafel plots of different catalysts for HER. (Reprinted with permission from ref. 254. Copyright@ 2011, American Chemical Society.) (d) TEM image of the MoS 2 / mesoporous graphene hybrid, (e) polarization curves, and (f) corresponding Tafel plots of different catalysts. (Reprinted with permission from ref. 256. Copyright@ 2013, WILEY-VCH.) (g) TEM image of the $\mathrm{MoS}_{2} / \mathrm{WC} /$ graphene composite, (h) polarization curves, and (i) corresponding Tafel plots of different catalysts. (Reprinted with permission from ref. 263. Copyright@ 2013, Royal Society of Chemistry.)

of electrons in the electrode during the oxygen-reduction process. Consequently, the composites exhibit excellent electrocatalytic performance for ORR (Fig. 10b), including high electrocatalytic activity, long-term durability, and high selectivity, all of which are superior to those observed in nitride sheets without graphene and commercial $\mathrm{Pt} / \mathrm{C}$ catalysts.

Graphitic carbon nitride $\left(\mathrm{g}-\mathrm{C}_{3} \mathrm{~N}_{4}\right)$ based materials are also becoming significant due to their unusual properties and promising applications as electrocatalysts. ${ }^{270}$ The combination of graphene and g- $\mathrm{C}_{3} \mathrm{~N}_{4}$ integrates their respective merits together, and the resulting composites show enhanced or unique properties. $^{269,271}$ Furthermore, the large amount of pyridine-like nitrogen in $\mathrm{g}-\mathrm{C}_{3} \mathrm{~N}_{4}$ can trap transition metals to form potential active sites. ${ }^{272}$ Hence, assemblies consisting of transition metals ( $\mathrm{Ti}^{273} \mathrm{Co}^{274} \mathrm{Fe},{ }^{275,276}$ etc.) and graphene/g- $\mathrm{C}_{3} \mathrm{~N}_{4}$ manifest improved electrocatalytic activity. ${ }^{277}$ Feng and coworkers demonstrated this concept by preparing titanium nitride/graphene nanocomposites, in which $\mathrm{C}_{3} \mathrm{~N}_{4}$ acts as both the nitrogen source and the template (Fig. 10c and d). ${ }^{278}$ With the aid of templates, uniform TiN nanoparticles can be attached with good dispersion on the graphene/CNT hybrid (Fig. 10e). The resultant hybrid exhibits better activity for ORR than bare TiN nanoparticles and comparable performance as the $\mathrm{Pt} / \mathrm{C}$ catalyst (Fig. 10f). In addition, good tolerance to methanol was also demonstrated. This dramatic enhancement is ascribed to a synergistic effect between TiN and the CNT/graphene hybrid, whose formal roles are to provide active sites for ORR and electron pathway respectively. ${ }^{279}$ On the other hand, there is evidence that metal ( $\mathrm{Fe}$ or $\mathrm{Co}$ ) coordination in $\mathrm{N}$-doped graphene will lead to far superior electrocatalytic activity. ${ }^{280}$

\subsection{Other carbon materials/graphene hybrids as electrocatalysts}

While metal/metal oxides-graphene hybrids electrocatalysts exhibit significantly higher electrocatalytic activity, they are often costly and more severely suffer from poor stability under strong acidic conditions. ${ }^{281}$ As a result, numerous research efforts have been made to develop efficient and durable electrocatalysts in acidic media. ${ }^{282} \mathrm{~N}$-doped carbon materials possess good electrocatalytic activity for ORR because of their increased active sites, good conductivity, and excellent stability in acidic media. ${ }^{267,283}$ To further improve the performance, CNTs have been investigated for their important role as the promoter in graphene-based electrocatalysts. ${ }^{284,285}$ In one embodiment, graphene, produced by partial unzipping of the outer walls of CNTs, is attached to the mostly intact inner walls (Fig. 11a). ${ }^{286}$ Upon the subsequent annealing process in $\mathrm{NH}_{3}$, the abundant edges and defect sites on graphene give rise to high ORR catalytic activity. The resultant N-doped graphene/ CNTs complex exhibits good activity and durability for ORR in both acidic and alkaline media (Fig. 11b). It is proposed that both iron impurities and the $\mathrm{N}$ doping effect contribute to the high electrocatalytic activity for ORR, similar to the above 

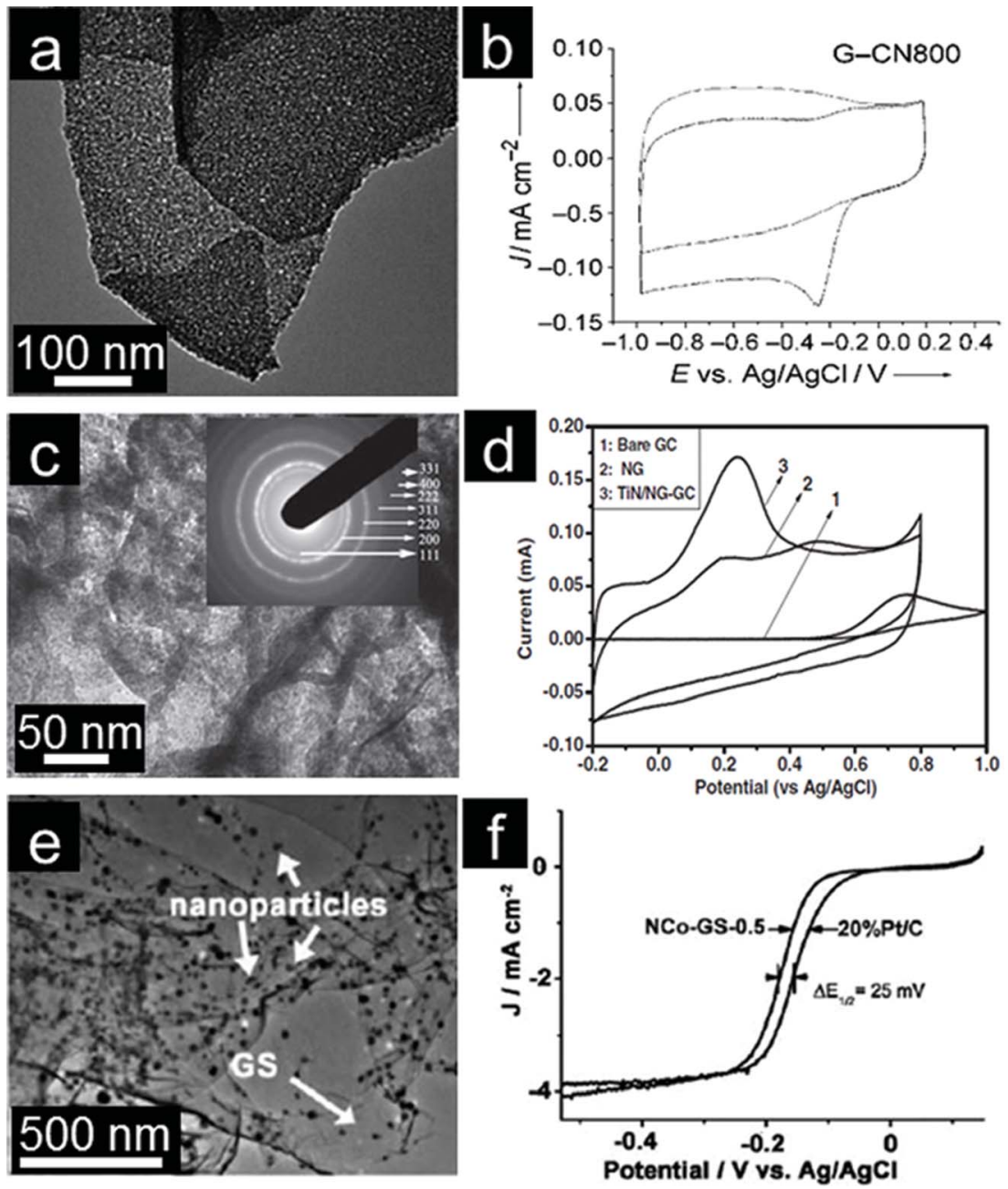

Fig. 10 (a) TEM image of graphene/carbon nitride composites and (b) corresponding $\mathrm{CV}_{\mathrm{s}}$ in $\mathrm{O}_{2}$ - and Ar-saturated $0.1 \mathrm{M} \mathrm{KOH}$ solution. (Reprinted with permission from ref. 265. Copyright $\odot$ 2011, WILEY-VCH.) (c) TEM image of TiN/graphene hybrids with the inset showing the SAED pattern and (d) corresponding CVs. (Reprinted with permission from ref. 278. Copyright@ 2011, WILEY-VCH.) (e) TEM image of Co-N-graphene and (f) corresponding RDE curves in $0.1 \mathrm{M} \mathrm{KOH}$ solution. (Reprinted with permission from ref. 279. Copyright@ 2013, Royal Society of Chemistry.)

discussed heteroatoms or transition metal doping into graphene. In order to avoid the use of harsh conditions and sophisticated instruments, Yu and coworkers reported a hydrothermal method to prepare $\mathrm{N}$-doped graphene/CNTs nanocomposites (Fig. 11c) ${ }^{287}$ The electrochemical results show that the nanocomposites undergo a 4e pathway for ORR with high positive onset potential, large peak current and high durability (Fig. 11d). The presence of graphene and CNTs synergistically enhances electrochemical activity for ORR. Furthermore, graphene/CNTs self-assemblies are also synthesized through electrostatic interaction between graphene and CNTs. These materials are applied as electrocatalysts for ORR in acidic media after $\mathrm{N}$ doping. ${ }^{285}$ In the assembled structure, CNTs act as circuits for facile electron transfer and spacers for preventing restacking of graphene layers. At the same time, the inter-graphene space introduced by CNTs facilitates the effective transport of reactants. ${ }^{288}$ Interestingly, ORR electrocatalysts made from N-doped graphene/CNTs frameworks retain their electrocatalytic activity even in the non-aqueous environment when employed as cathode electrocatalysts for $\mathrm{Li}^{-} \mathrm{O}_{2}$ batteries. ${ }^{289} \mathrm{High}$ surface area, porous structure, and good conductivity are considered as important factors for high electrocatalytic activity. As such, Qiao and coworkers recently reported the in situ growth of $\mathrm{N}$-doped graphene on hierarchical ordered porous carbon (Fig. 11e). As expected, synergistically enhanced ORR performance was observed (Fig. 11f). ${ }^{290}$

\section{Other novel graphene-based electrocatalysts}

Metal-organic frameworks (MOFs), a new class of porous crystalline materials, may serve as an outstanding candidate in this field based on their high surface areas, controllable structures and excellent electrochemical properties. ${ }^{291}$ For example, Loh and coworkers used pyridine-functionalized graphene as a support for MOF particles. The linkage between graphene and pyridine ligands in MOF indeed increases the electrocatalytic activity of MOF/graphene hybrids and facilitates ORR via 4e reaction. In addition, methanol crossover is also minimized in 

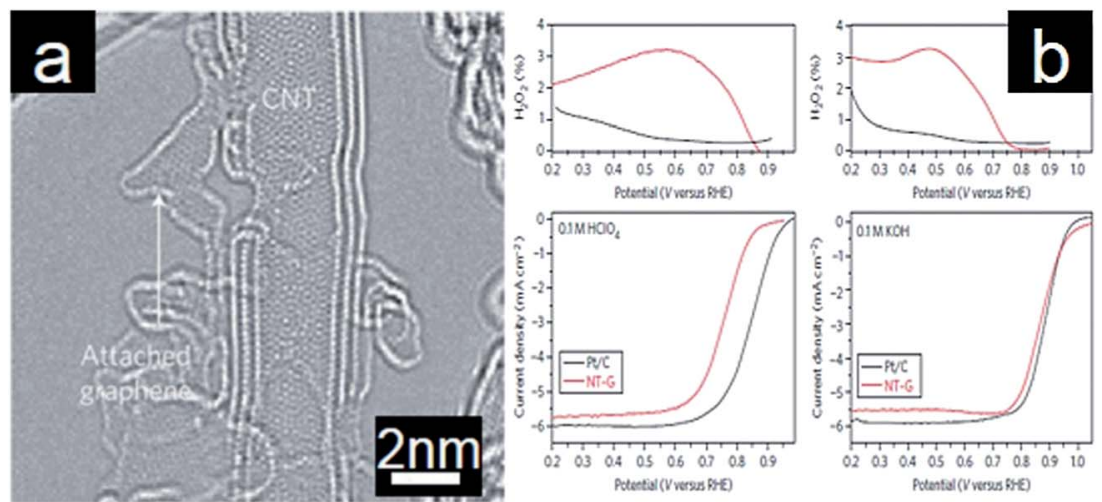

Petertal (Vuress ste Potental(Vwres fite)
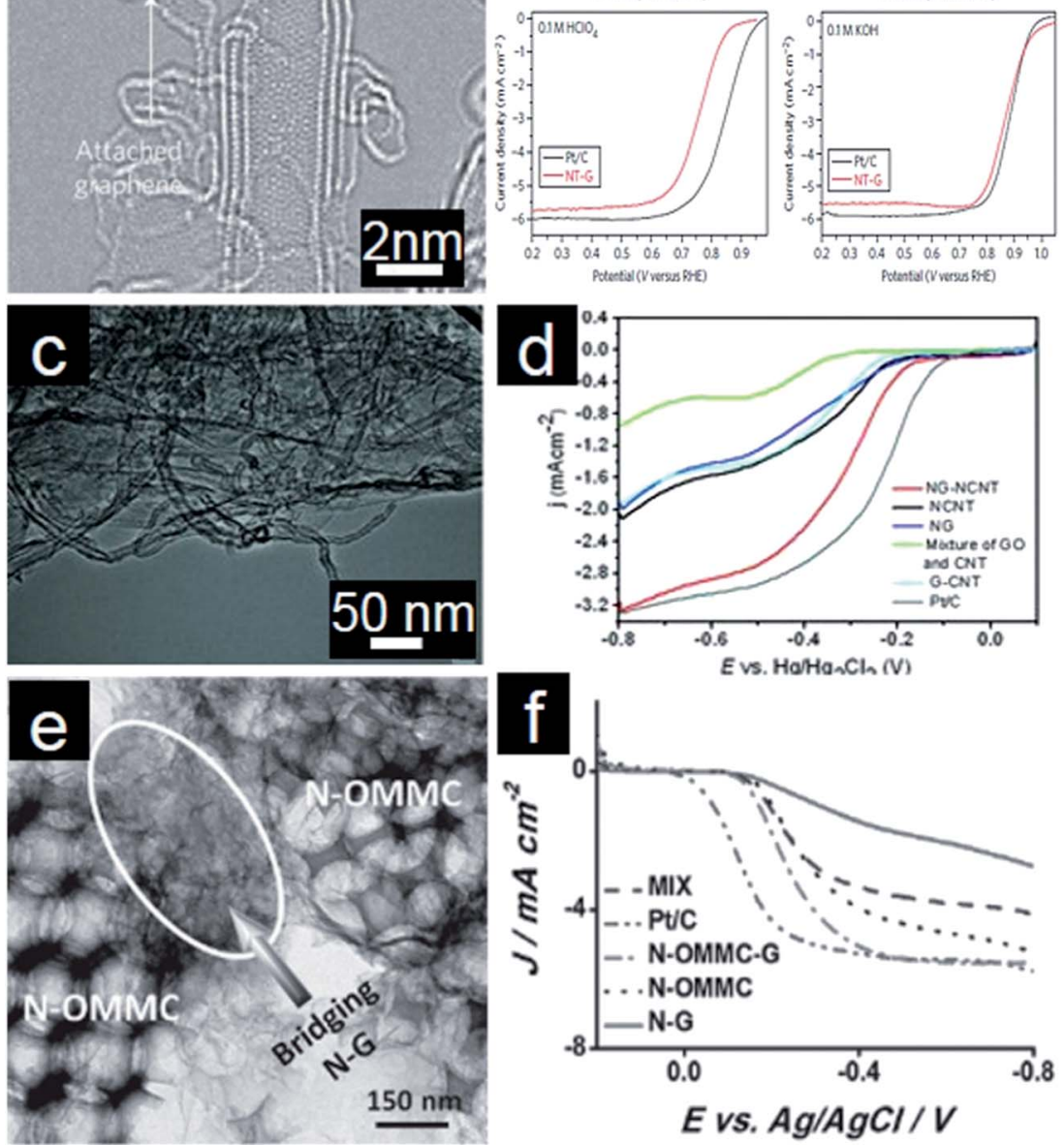

E vs. Ag/AgCl/V

Fig. 11 (a) TEM image of $\mathrm{N}$-doped graphene/CNT composites and (b) their corresponding rotating ring-disk electrode (RRDE) polarization curves in $\mathrm{O}_{2}$ saturated $0.1 \mathrm{M} \mathrm{HClO}_{4}$ and $0.1 \mathrm{M} \mathrm{KOH}$ solution. (Reprinted with permission from ref. 286. Copyright $\odot$ 2012, Nature Publishing Group.) (c) TEM of N-doped graphene/CNT nanocomposites and (d) RDE curves of different catalysts for $\mathrm{ORR}$ in $\mathrm{O}_{2}$-saturated $0.1 \mathrm{M}$ KOH solution (20 mV s$\left.{ }^{-1} ; 1600 \mathrm{rpm}\right)$. (Reprinted with permission from ref. 287. Copyright $\odot 2013$, WILEY-VCH.) (e) TEM image of N-doped graphene on ordered porous carbon and (f) RDE curves of different catalysts for ORR in $\mathrm{O}_{2}$-saturated $0.1 \mathrm{M} \mathrm{KOH}$ (1600 rpm). (Reprinted with permission from ref. 290. Copyright@ 2013, WILEY-VCH.)

this MOF/graphene hybrid because of its inactivity to methanol oxidation. ${ }^{292}$ The integration of GO and a Cu-centered MOF shows good performance as a tri-functional electrocatalyst for HER, OER and ORR. In polymer electrolyte membrane fuel cell testing, the GO incorporated $\mathrm{Cu}-\mathrm{MOF}$ is able to deliver $76 \%$ of power density of the commercial Pt catalyst. The enhanced electrocatalytic properties and stability under acidic conditions of the MOF/graphene composite are attributed to the unique porous scaffold structure, improved charge transport and synergistic interactions between graphene and MOF. ${ }^{293,294}$

\section{Conclusions and perspectives}

The search for highly efficient electrocatalysts with excellent stability is of great importance for sustainable energy technologies including fuel cells, Li-air batteries and water splitting.
Graphene has emerged as a unique material because of its 2D structure, good electrical conductivity and high surface area. Graphene is therefore expected to be an important component for developing alternative electrocatalysts. In this review, we have systematically summarized the recent progress in preparation of graphene-based hybrids with controlled size, composition, shape/morphology and structure, and highlighted their superior electrochemical activity, excellent stability and selectivity. This review is intended to provide valuable insights for researchers to speed up innovation in this area.

Although significant advance has been achieved in the area of graphene-based hybrid electrocatalysts, this field is still in its early stage from the practical perspective, especially in the direction of non-metal/graphene nanocomposites. Further development of graphene-based hybrid electrocatalysts is being impeded by the challenges listed below. Doping of heteroatoms 
is an efficient way to tune properties of graphene and increase the active sites on the graphene surface. However, the electrocatalytic performance of these doped catalysts is still far from satisfactory, mainly due to issues such as low doping content and the lack of control over the doping process. Selective and tunable coordination of heteroatoms into graphene may help to increase the number of exposed active sites and improve their activity, thus enhancing the electrochemical performance. Combined experimental and theoretical studies are thus required to develop a method for controlled doping of heteroatoms into designated sites, and to understand the proposed mechanism on the catalytic activity of modified graphene.

Graphene is a unique support for noble metal nanocatalysts. Graphene supported noble metal nanoparticles possessing controlled size, shape, morphology and composition can enhance electrochemical performance for fuel oxidation, oxygen reduction and water splitting reactions. However, the migration, aggregation and dissolution in harsh electrochemical environments as well as the weak CO tolerance would greatly affect their practical exploitation. Hybrid structures constructed from modified graphene and alloyed metal nanoparticles could be alternative efficient electrocatalysts with designed stability and selectivity. Coupling graphene with non-metals leads to superior activity and lowers the cost. But electrochemical performance of such hybrid materials is strongly dependent on individual components and their interactions with each other. Also, mechanisms of these graphene based nanohybrids working in energy related systems remain largely unclear. Thus, further studies are required to understand the underlying complex interactions. Finally, exploration of new graphene-based hybrids with novel structures and appropriate electronic properties such as $\mathrm{MOF} /$ graphene can further expand the materials database for efficient electrocatalysts.

Undoubtedly, graphene-based nanohybrids are likely to find real significance for sustainable electrochemical energy conversion and storage. Research efforts devoted to these directions will surely pay off in the near future.

\section{References}

1 C. Xu, B. Xu, Y. Gu, Z. Xiong, J. Sun and X. S. Zhao, Energy Environ. Sci., 2013, 6, 1388.

2 F. Cheng and J. Chen, Chem. Soc. Rev., 2012, 41, 2172.

3 X. Zhao, M. Yin, L. Ma, L. Liang, C. Liu, J. Liao, T. Lu and W. Xing, Energy Environ. Sci., 2011, 4, 2736.

4 Y. Liang, Y. Li, H. Wang and H. Dai, J. Am. Chem. Soc., 2013, 135, 2013.

5 W. Yu, M. D. Porosoff and J. G. Chen, Chem. Rev., 2012, 112, 5780.

6 P. V. Kamat, J. Phys. Chem. Lett., 2012, 3, 3404.

7 D. S. Su, S. Perathoner and G. Centi, Chem. Rev., 2013, 113, 5782.

8 K. S. Novoselov, A. K. Geim, S. V. Morozov, D. Jiang, Y. Zhang, S. V. Dubonos, I. V. Grigorieva and A. A. Firsov, Science, 2004, 306, 666.

9 X. Wan, Y. Huang and Y. Chen, Acc. Chem. Res., 2012, 45, 598.
10 X. Huang, X. Qi, F. Boey and H. Zhang, Chem. Soc. Rev., 2012, 41, 666.

11 M. Pumera, Chem. Soc. Rev., 2010, 39, 4146.

12 X. Huang, Z. Yin, S. Wu, X. Qi, Q. He, Q. Zhang, Q. Yan, F. Boey and H. Zhang, Small, 2011, 7, 1876.

13 N. G. Sahoo, Y. Pan, L. Li and S. H. Chan, Adv. Mater., 2012, 24, 4203.

14 S. Guo and S. Dong, Chem. Soc. Rev., 2011, 40, 2644.

15 H. Wang and H. Dai, Chem. Soc. Rev., 2013, 42, 3088.

16 L. L. Zhang, R. Zhou and X. S. Zhao, J. Mater. Chem., 2010, 20, 5983.

17 D. A. C. Brownson, D. K. Kampouris and C. E. Banks, J. Power Sources, 2011, 196, 4873.

18 M. Pumera, Energy Environ. Sci., 2011, 4, 668.

19 Y. Sun, Q. Wu and G. Shi, Energy Environ. Sci., 2011, 4, 1113. 20 H.-J. Choi, S.-M. Jung, J.-M. Seo, D. W. Chang, L. Dai and J.-B. Baek, Nano Energy, 2012, 1, 534.

21 Y. Huang, J. Liang and Y. Chen, Small, 2012, 8, 1805.

22 T. Kuila, A. K. Mishra, P. Khanra, N. H. Kim and J. H. Lee, Nanoscale, 2013, 5, 52.

23 B. F. Machado and P. Serp, Catal. Sci. Technol., 2012, 2, 54.

24 C. C. Huang, C. Li and G. Q. Shi, Energy Environ. Sci., 2012, $5,8848$.

25 S. H. Hur and J.-N. Park, Asia-Pac. J. Chem. Eng., 2013, 8, 218.

26 J. Hou, Y. Shao, M. W. Ellis, R. B. Moore and B. Yi, Phys. Chem. Chem. Phys., 2011, 13, 15384.

27 C. Zhu and S. Dong, Nanoscale, 2013, 5, 1753.

28 H. Wang, T. Maiyalagan and X. Wang, ACS Catal., 2012, 2, 781.

29 L. S. Panchakarla, K. S. Subrahmanyam, S. K. Saha, A. Govindaraj, H. R. Krishnamurthy, U. V. Waghmare and C. N. R. Rao, Adv. Mater., 2009, 21, 4726.

30 Y. Y. Shao, S. Zhang, M. H. Engelhard, G. S. Li, G. C. Shao, Y. Wang, J. Liu, I. A. Aksay and Y. H. Lin, J. Mater. Chem., 2010, 20, 7491.

31 D. Deng, X. Pan, L. Yu, Y. Cui, Y. Jiang, J. Qi, W.-X. Li, Q. Fu, X. Ma, Q. Xue, G. Sun and X. Bao, Chem. Mater., 2011, 23, 1188.

32 H. R. Byon, J. Suntivich and Y. Shao-Horn, Chem. Mater., 2011, 23, 3421.

33 Z. Yang, H. G. Nie, X. Chen, X. H. Chen and S. M. Huang, J. Power Sources, 2013, 236, 238.

34 L. Lai, J. R. Potts, D. Zhan, L. Wang, C. K. Poh, C. Tang, H. Gong, Z. Shen, J. Lin and R. S. Ruoff, Energy Environ. Sci., 2012, 5, 7936.

35 C. H. Choi, M. W. Chung, S. H. Park and S. I. Woo, RSC Adv., 2013, 3, 4246.

36 K. A. Kurak and A. B. Anderson, J. Phys. Chem. C, 2009, 113, 6730.

37 Z. Luo, S. Lim, Z. Tian, J. Shang, L. Lai, B. MacDonald, C. Fu, Z. Shen, T. Yu and J. Lin, J. Mater. Chem., 2011, 21, 8038.

38 S. Yasuda, L. Yu, J. Kim and K. Murakoshi, Chem. Commun., 2013, 49, 9627.

39 D. Geng, Y. Chen, Y. Chen, Y. Li, R. Li, X. Sun, S. Ye and S. Knights, Energy Environ. Sci., 2011, 4, 760. 
40 Y. Li, Y. Zhao, H. Cheng, Y. Hu, G. Shi, L. Dai and L. Qu, J. Am. Chem. Soc., 2011, 134, 15.

41 Q. Li, S. Zhang, L. Dai and L.-s. Li, J. Am. Chem. Soc., 2012, 134, 18932.

42 Y. Liu and P. Wu, ACS Appl. Mater. Interfaces, 2013, 5, 3362.

43 T. Palaniselvam, H. B. Aiyappa and S. Kurungot, J. Mater. Chem., 2012, 22, 23799.

44 X. Jia, J. Campos-Delgado, M. Terrones, V. Meunier and M. S. Dresselhaus, Nanoscale, 2011, 3, 86.

45 S. Xin, Y.-G. Guo and L.-J. Wan, Acc. Chem. Res., 2012, 45, 1759.

46 Y. Li, J. Wang, X. Li, D. Geng, R. Li and X. Sun, Chem. Commun., 2011, 47, 9438.

47 E. Yoo and H. Zhou, ACS Nano, 2011, 5, 3020.

48 J. Xiao, D. Mei, X. Li, W. Xu, D. Wang, G. L. Graff, W. D. Bennett, Z. Nie, L. V. Saraf, I. A. Aksay, J. Liu and J.-G. Zhang, Nano Lett., 2011, 11, 5071.

49 Z.-L. Wang, D. Xu, J.-J. Xu, L.-L. Zhang and X.-B. Zhang, Adv. Funct. Mater., 2012, 22, 3699.

50 E. Yoo, J. Nakamura and H. Zhou, Energy Environ. Sci., 2012, $5,6928$.

51 Y. L. Li, J. J. Wang, X. F. Li, D. S. Geng, M. N. Banis, R. Y. Li and X. L. Sun, Electrochem. Commun., 2012, 18, 12.

52 J. P. Paraknowitsch and A. Thomas, Energy Environ. Sci., 2013, 6, 2839.

53 M. Seredych, J.-C. Idrobo and T. J. Bandosz, J. Mater. Chem. A, 2013, 1, 7059.

54 I.-Y. Jeon, S. Zhang, L. Zhang, H.-J. Choi, J.-M. Seo, Z. Xia, L. Dai and J.-B. Baek, Adv. Mater., 2013, 25, 6138.

55 Z. Yang, Z. Yao, G. F. Li, G. Y. Fang, H. G. Nie, Z. Liu, X. M. Zhou, X. Chen and S. M. Huang, ACS Nano, 2012, 6, 205.

56 Y. L. Li, J. J. Wang, X. F. Li, D. S. Geng, M. N. Banis, Y. J. Tang, D. N. Wang, R. Y. Li, T. K. Sham and X. L. Sun, J. Mater. Chem., 2012, 22, 20170.

57 Z. P. Jin, H. G. Nie, Z. Yang, J. Zhang, Z. Liu, X. J. Xu and S. M. Huang, Nanoscale, 2012, 4, 6455.

58 Z. Yao, H. Nie, Z. Yang, X. Zhou, Z. Liu and S. Huang, Chem. Commun., 2012, 48, 1027.

59 Z. W. Liu, F. Peng, H. J. Wang, H. Yu, W. X. Zheng and J. A. Yang, Angew. Chem., Int. Ed., 2011, 50, 3257.

60 C. Zhang, N. Mahmood, H. Yin, F. Liu and Y. Hou, Adv. Mater., 2013, 25, 4932.

61 H. Wang, Y. Zhou, D. Wu, L. Liao, S. Zhao, H. Peng and Z. Liu, Small, 2013, 9, 1316.

62 Z.-H. Sheng, H.-L. Gao, W.-J. Bao, F.-B. Wang and X.-H. Xia, J. Mater. Chem., 2012, 22, 390.

63 S.-A. Wohlgemuth, R. J. White, M.-G. Willinger, M.-M. Titirici and M. Antonietti, Green Chem., 2012, 14, 1515.

64 Y. Zhao, L. Yang, S. Chen, X. Wang, Y. Ma, Q. Wu, Y. Jiang, W. Qian and Z. Hu, J. Am. Chem. Soc., 2013, 135, 1201.

65 C. H. Choi, M. W. Chung, H. C. Kwon, S. H. Park and S. I. Woo, J. Mater. Chem. A, 2013, 1, 3694.

66 S. Wang, E. Iyyamperumal, A. Roy, Y. Xue, D. Yu and L. Dai, Angew. Chem., Int. Ed., 2011, 50, 11756.
67 C. H. Choi, M. W. Chung, S. H. Park and S. I. Woo, Phys. Chem. Chem. Phys., 2013, 15, 1802.

68 S. Wang, L. Zhang, Z. Xia, A. Roy, D. W. Chang, J.-B. Baek and L. Dai, Angew. Chem., Int. Ed., 2012, 51, 4209.

69 Z.-S. Wu, A. Winter, L. Chen, Y. Sun, A. Turchanin, X. Feng and K. Müllen, Adv. Mater., 2012, 24, 5130.

70 Y. Zheng, Y. Jiao, L. Ge, M. Jaroniec and S. Z. Qiao, Angew. Chem., Int. Ed., 2013, 52, 3110.

71 J. X. Xu, G. F. Dong, C. H. Jin, M. H. Huang and L. H. Guan, ChemSusChem, 2013, 6, 493.

72 S. Yang, L. Zhi, K. Tang, X. Feng, J. Maier and K. Müllen, Adv. Funct. Mater., 2012, 22, 3634.

73 J. Liang, Y. Jiao, M. Jaroniec and S. Z. Qiao, Angew. Chem., Int. Ed., 2012, 51, 11496.

74 R. Bashyam and P. Zelenay, Nature, 2006, 443, 63.

75 M. Lefèvre, E. Proietti, F. Jaouen and J.-P. Dodelet, Science, 2009, 324, 71.

76 X. Yuan, X. Zeng, H.-J. Zhang, Z.-F. Ma and C.-Y. Wang, J. Am. Chem. Soc., 2010, 132, 1754.

77 G. Wu, K. L. More, C. M. Johnston and P. Zelenay, Science, 2011, 332, 443.

78 R. J. Toh, H. L. Poh, Z. Sofer and M. Pumera, Chem.-Asian J., 2013, 8, 1295.

79 K. Parvez, S. Yang, Y. Hernandez, A. Winter, A. Turchanin, X. Feng and K. Müllen, ACS Nano, 2012, 6, 9541.

80 K. Kamiya, K. Hashimoto and S. Nakanishi, Chem. Commun., 2012, 48, 10213.

81 H. Peng, Z. Mo, S. Liao, H. Liang, L. Yang, F. Luo, H. Song, Y. Zhong and B. Zhang, Sci. Rep., 2013, 3, 1765.

82 S. Jiang, C. Zhu and S. Dong, J. Mater. Chem. A, 2013, 1, 3593.

83 Y. Zhao, K. Watanabe and K. Hashimoto, J. Mater. Chem. A, 2013, 1, 1450.

84 X. Fu, Y. Liu, X. Cao, J. Jin, Q. Liu and J. Zhang, Appl. Catal., $B$, 2013, 130-131, 143.

85 K. Niu, B. Yang, J. Cui, J. Jin, X. Fu, Q. Zhao and J. Zhang, J. Power Sources, 2013, 243, 65.

86 H. Liu, Y. Liu and D. Zhu, J. Mater. Chem., 2011, 21, 3335.

87 D. Wei, Y. Liu, Y. Wang, H. Zhang, L. Huang and G. Yu, Nano Lett., 2009, 9, 1752.

88 V. Georgakilas, M. Otyepka, A. B. Bourlinos, V. Chandra, N. Kim, K. C. Kemp, P. Hobza, R. Zboril and K. S. Kim, Chem. Rev., 2012, 112, 6156.

89 L. Dai, Acc. Chem. Res., 2012, 46, 31.

90 Q. Tang, Z. Zhou and Z. Chen, Nanoscale, 2013, 5, 4541.

91 S. Wang, D. Yu, L. Dai, D. W. Chang and J.-B. Baek, ACS Nano, 2011, 5, 6202.

92 C. Z. Zhang, R. Hao, H. B. Liao and Y. L. Hou, Nano Energy, 2013, 2, 88.

93 M. S. Ahmed and S. Jeon, J. Power Sources, 2012, 218, 168.

94 J. P. Song, J. Qiao, S. M. Shuang, Y. J. Guo and C. Dong, J. Mater. Chem. A, 2012, 22, 602.

95 Y. Zhang, G. Mo, X. Li and J. Ye, J. Power Sources, 2012, 197, 93.

96 G. Lv, L. Cui, Y. Wu, Y. Liu, T. Pu and X. He, Phys. Chem. Chem. Phys., 2013, 15, 13093. 
97 H. Tang, H. Yin, J. Wang, N. Yang, D. Wang and Z. Tang, Angew. Chem., Int. Ed., 2013, 52, 5585.

98 C. Zhang, R. Hao, H. Yin, F. Liu and Y. Hou, Nanoscale, 2012, 4, 7326.

99 Y. Jiang, Y. Lu, X. Lv, D. Han, Q. Zhang, L. Niu and W. Chen, ACS Catal., 2013, 3, 1263.

100 M. Giovanni, H. L. Poh, A. Ambrosi, G. J. Zhao, Z. Sofer, F. Sanek, B. Khezri, R. D. Webster and M. Pumera, Nanoscale, 2012, 4, 5002.

101 J. M. Campelo, D. Luna, R. Luque, J. M. Marinas and A. A. Romero, ChemSusChem, 2009, 2, 18.

102 B. Y. Xia, W. T. Ng, H. B. Wu, X. Wang and X. W. Lou, Angew. Chem., Int. Ed., 2012, 51, 7213.

103 B. Seger and P. V. Kamat, J. Phys. Chem. C, 2009, 113, 7990.

104 D. Chen, L. Tang and J. Li, Chem. Soc. Rev., 2010, 39, 3157. 105 W. Qian, R. Hao, J. Zhou, M. Eastman, B. A. Manhat, Q. Sun, A. M. Goforth and J. Jiao, Carbon, 2013, 52, 595.

106 L. N. Gao, W. B. Yue, S. S. Tao and L. Z. Fan, Langmuir, 2013, 29, 957.

107 E. Antolini, Appl. Catal., B, 2012, 123-124, 52.

108 R. Siburian, T. Kondo and J. Nakamura, J. Phys. Chem. C, 2013, 117, 3635.

109 J. D. Qiu, G. C. Wang, R. P. Liang, X. H. Xia and H. W. Yu, J. Phys. Chem. C, 2011, 115, 15639.

110 E. Yoo, T. Okata, T. Akita, M. Kohyama, J. Nakamura and I. Honma, Nano Lett., 2009, 9, 2255.

111 B. Y. Xia, H. B. Wu, X. Wang and X. W. Lou, Angew. Chem., Int. Ed., 2013, 52, 12337.

112 Y. P. Xiao, S. Wan, X. Zhang, J. S. Hu, Z. D. Wei and L. J. Wan, Chem. Commun., 2012, 48, 10331.

113 B. Y. Xia, H. Bin Wu, Y. Yan, X. W. Lou and X. Wang, J. Am. Chem. Soc., 2013, 135, 9480.

114 R. Wang, D. C. Higgins, M. A. Hoque, D. Lee, F. Hassan and Z. Chen, Sci. Rep., 2013, 3, 2431.

115 Z. M. Luo, L. H. Yuwen, B. Q. Bao, J. Tian, X. R. Zhu, L. X. Weng and L. H. Wang, J. Mater. Chem., 2012, 22, 7791.

116 X. Yang, Q. Yang, J. Xu and C.-S. Lee, J. Mater. Chem. A, 2012, 22, 8057.

117 W. He, H. J. Jiang, Y. Zhou, S. D. Yang, X. Z. Xue, Z. Q. Zou, X. G. Zhang, D. L. Akins and H. Yang, Carbon, 2012, 50, 265.

118 S. Zhang, Y. Y. Shao, H. G. Liao, J. Liu, I. A. Aksay, G. P. Yin and Y. H. Lin, Chem. Mater., 2011, 23, 1079.

119 Z. Y. Huang, H. H. Zhou, C. H. Li, F. Y. Zeng, C. P. Fu and Y. F. Kuang, J. Mater. Chem., 2012, 22, 1781.

120 H. J. Kim, S. M. Choi, M. H. Seo, S. Green, G. W. Huber and W. B. Kim, Electrochem. Commun., 2011, 13, 890.

121 G. Wei, Y. Zhang, S. Steckbeck, Z. Su and Z. Li, J. Mater. Chem., 2012, 22, 17190.

122 Q. Yue, K. Zhang, X. Chen, L. Wang, J. Zhao, J. Liu and J. Jia, Chem. Commun., 2010, 46, 3369.

123 B. P. Vinayan and S. Ramaprabhu, Nanoscale, 2013, 5, 5109.

124 B. Y. Xia, H. B. Wu, X. Wang and X. W. Lou, J. Am. Chem. Soc., 2012, 134, 13934.

125 F. Han, X. M. Wang, J. Lian and Y. Z. Wang, Carbon, 2012, 50, 5498.
126 Y. Z. Zhang, Y. E. Gu, S. X. Lin, J. P. Wei, Z. H. Wang, C. M. Wang, Y. L. Du and W. C. Ye, Electrochim. Acta, 2011, 56, 8746.

127 S. J. Guo, S. J. Dong and E. K. Wang, ACS Nano, 2010, 4, 547.

128 S. Guo, S. Zhang and S. Sun, Angew. Chem., Int. Ed., 2013, 52, 8526.

129 Y. Xia, Y. Xiong, B. Lim and S. E. Skrabalak, Angew. Chem., Int. Ed., 2009, 48, 60.

130 K. Zhou and Y. Li, Angew. Chem., Int. Ed., 2012, 51, 602.

131 S. Guo and S. Dong, J. Mater. Chem., 2011, 21, 16704.

132 P. V. Kamat, J. Phys. Chem. Lett., 2011, 2, 242.

133 S. Guo, D. Li, H. Zhu, S. Zhang, N. M. Markovic, V. R. Stamenkovic and S. Sun, Angew. Chem., Int. Ed., 2013, 52, 3465.

134 M. T. M. Koper, Nanoscale, 2011, 3, 2054.

135 T. Jin, S. Guo, J.-l. Zuo and S. Sun, Nanoscale, 2013, 5, 160.

136 S. Y. Wang, X. Wang and S. P. Jiang, Phys. Chem. Chem. Phys., 2011, 13, 7187.

137 S. Guo and S. Sun, J. Am. Chem. Soc., 2012, 134, 2492.

138 B. P. Vinayan, R. Nagar and S. Ramaprabhu, J. Mater. Chem., 2012, 22, 25325.

139 D. P. He, K. Cheng, T. Peng, X. L. Sun, M. Pan and S. C. Mu, J. Mater. Chem., 2012, 22, 21298.

140 J. H. Shim, J. E. Kim, Y.-B. Cho, C. Lee and Y. Lee, Phys. Chem. Chem. Phys., 2013, 15, 15365.

141 H. Huang and X. Wang, J. Mater. Chem., 2012, 22, 22533.

142 X. Chen, G. Wu, J. Chen, X. Chen, Z. Xie and X. Wang, J. Am. Chem. Soc., 2011, 133, 3693.

143 M. M. Liu, Y. Z. Lu and W. Chen, Adv. Funct. Mater., 2013, 23, 1289.

144 Y. Choi, M. Gu, J. Park, H. K. Song and B. S. Kim, Adv. Energy Mater., 2012, 2, 1510.

145 H. Yin, H. Tang, D. Wang, Y. Gao and Z. Tang, ACS Nano, 2012, 6, 8288.

146 S. M. Alia, K. Duong, T. Liu, K. Jensen and Y. Yan, ChemSusChem, 2012, 5, 1619.

147 D. Yu, J. Yao, L. Qiu, Y. Wu, L. Li, Y. Feng, Q. Liu, D. Li and H. Wang, RSC Adv., 2013, 3, 11552.

148 Y. Zhu, S. Murali, W. Cai, X. Li, J. W. Suk, J. R. Potts and R. S. Ruoff, Adv. Mater., 2010, 22, 3906.

149 I. Fampiou and A. Ramasubramaniam, J. Phys. Chem. C, 2012, 116, 6543.

150 O. C. Compton and S. T. Nguyen, Small, 2010, 6, 711.

151 L. Yan, Y. B. Zheng, F. Zhao, S. Li, X. Gao, B. Xu, P. S. Weiss and Y. Zhao, Chem. Soc. Rev., 2012, 41, 97.

152 B. Xiong, Y. K. Zhou, Y. Y. Zhao, J. Wang, X. Chen, R. O'Hayre and Z. P. Shao, Carbon, 2013, 52, 181.

153 D. Wei and Y. Liu, Adv. Mater., 2010, 22, 3225.

154 R. Kou, Y. Y. Shao, D. H. Wang, M. H. Engelhard, J. H. Kwak, J. Wang, V. V. Viswanathan, C. M. Wang, Y. H. Lin, Y. Wang, I. A. Aksay and J. Liu, Electrochem. Commun., 2009, 11, 954.

155 A. Ghosh, S. Basu and A. Verma, Fuel Cells, 2013, 13, 355.

156 Q. Wang, M. M. Song, C. L. Chen, W. P. Hu and X. K. Wang, ChemPlusChem, 2012, 77, 432.

157 Y. M. Tan, C. F. Xu, G. X. Chen, N. F. Zheng and Q. J. Xie, Energy Environ. Sci., 2012, 5, 6923. 
158 J. N. Tiwari, K. Nath, S. Kumar, R. N. Tiwari, K. C. Kemp, N. H. Le, D. H. Youn, J. S. Lee and K. S. Kim, Nat. Commun., 2013, 4, 2221.

159 J. J. Shi, G. H. Yang and J. J. Zhu, J. Mater. Chem. A, 2011, 21, 7343.

160 Z. H. Wang, J. F. Xia, X. M. Guo, Y. Z. Xia, S. Y. Yao, F. F. Zhang, Y. H. Li and L. H. Xia, Adv. Mater., 2013, 5, 483.

161 K. W. Nam, J. Song, K. H. Oh, M. J. Choo, H. Park, J. K. Park and J. W. Choi, Carbon, 2012, 50, 3739.

162 A. Y. W. Sham and S. M. Notley, Soft Matter, 2013, 9, 6645.

163 Z. Cui, C. X. Guo and C. M. Li, J. Mater. Chem. A, 2013, 1, 6687.

164 S. Yang, C. Shen, Y. Liang, H. Tong, W. He, X. Shi, X. Zhang and H.-j. Gao, Nanoscale, 2011, 3, 3277.

165 Y. C. Zhao, L. Zhan, J. N. Tian, S. L. Nie and Z. Ning, Electrochim. Acta, 2011, 56, 1967.

166 D. H. Deng, L. Yu, X. L. Pan, S. Wang, X. Q. Chen, P. Hu, L. X. Sun and X. H. Bao, Chem. Commun., 2011, 47, 10016. 167 D. Chen, H. Feng and J. Li, Chem. Rev., 2012, 112, 6027.

168 J. Peng, W. Gao, B. K. Gupta, Z. Liu, R. Romero-Aburto, L. Ge, L. Song, L. B. Alemany, X. Zhan, G. Gao, S. A. Vithayathil, B. A. Kaipparettu, A. A. Marti, T. Hayashi, J.-J. Zhu and P. M. Ajayan, Nano Lett., 2012, $12,844$.

169 J. Shen, Y. Zhu, X. Yang and C. Li, Chem. Commun., 2012, 48, 3686.

170 G. He, Y. Song, K. Liu, A. Walter, S. Chen and S. Chen, ACS Catal., 2013, 3, 831.

171 X. Yan, Q. Li and L.-s. Li, J. Am. Chem. Soc., 2012, 134, 16095.

172 C. Wu, X. Huang, G. Wang, L. Lv, G. Chen, G. Li and P. Jiang, Adv. Funct. Mater., 2013, 23, 506.

173 J. Zhang, F. Zhao, Z. Zhang, N. Chen and L. Qu, Nanoscale, 2013, 5, 3112.

174 P. V. Kamat, J. Phys. Chem. Lett., 2009, 1, 520.

175 D. Wu, F. Zhang, H. Liang and X. Feng, Chem. Soc. Rev., 2012, 41, 6160.

176 B. G. Choi, M. Yang, W. H. Hong, J. W. Choi and Y. S. Huh, ACS Nano, 2012, 6, 4020.

177 K. Chen, L. Chen, Y. Chen, H. Bai and L. Li, J. Mater. Chem., 2012, 22, 20968.

178 D. A. C. Brownson, L. C. S. Figueiredo-Filho, X. Ji, M. Gomez-Mingot, J. Iniesta, O. Fatibello-Filho, D. K. Kampouris and C. E. Banks, J. Mater. Chem. A, 2013, 1, 5962.

179 S. Nardecchia, D. Carriazo, M. L. Ferrer, M. C. Gutierrez and F. del Monte, Chem. Soc. Rev., 2013, 42, 794.

180 S. Sattayasamitsathit, Y. Gu, K. Kaufmann, W. Jia, X. Xiao, M. Rodriguez, S. Minteer, J. Cha, D. B. Burckel, C. Wang, R. Polsky and J. Wang, J. Mater. Chem. A, 2013, 1, 1639.

181 S. Guo, D. Wen, Y. Zhai, S. Dong and E. Wang, ACS Nano, 2010, 4, 3959.

182 C. G. Hu, H. H. Cheng, Y. Zhao, Y. Hu, Y. Liu, L. M. Dai and L. T. Qu, Adv. Mater., 2012, 24, 5493.

183 Y. Si and E. T. Samulski, Chem. Mater., 2008, 20, 6792.

184 Y. Tang, Z. Yang and X. Dai, Phys. Chem. Chem. Phys., 2012, 14, 16566.
185 C. S. Chen and F. M. Pan, Appl. Catal., B, 2009, 91, 663.

186 B. Y. Xia, H. B. Wu, J. S. Chen, Z. Wang, X. Wang and X. W. Lou, Phys. Chem. Chem. Phys., 2012, 14, 473.

187 Z. L. Wen, S. D. Yang, Y. Y. Liang, W. He, H. Tong, L. A. Hao, X. G. Zhang and Q. J. Song, Electrochim. Acta, 2010, 56, 139.

188 H. Huang, Q. Chen, M. He, X. Sun and X. Wang, J. Power Sources, 2013, 239, 189.

189 X. Li, W. Qi, D. Mei, M. L. Sushko, I. Aksay and J. Liu, Adv. Mater., 2012, 24, 5136.

190 J. Luo, H. D. Jang, T. Sun, L. Xiao, Z. He, A. P. Katsoulidis, M. G. Kanatzidis, J. M. Gibson and J. Huang, ACS Nano, 2011, 5, 8943.

191 R. Kou, Y. Shao, D. Mei, Z. Nie, D. Wang, C. Wang, V. V. Viswanathan, S. Park, I. A. Aksay, Y. Lin, Y. Wang and J. Liu, J. Am. Chem. Soc., 2011, 133, 2541.

192 B. Y. Xia, B. Wang, H. B. Wu, Z. Liu, X. Wang and X. W. Lou, J. Mater. Chem., 2012, 22, 16499.

193 X. Wang, X. Y. Li, D. P. Liu, S. Y. Song and H. J. Zhang, Chem. Commun., 2012, 48, 2885.

194 R. Liu, H. H. Zhou, J. Liu, Y. Yao, Z. Y. Huang, C. P. Fu and Y. F. Kuang, Electrochem. Commun., 2013, 26, 63.

195 D. Yu and L. Dai, J. Phys. Chem. Lett., 2009, 1, 467.

196 A. Marinkas, F. Arena, J. Mitzel, G. M. Prinz, A. Heinzel, V. Peinecke and H. Natter, Carbon, 2013, 58, 139.

197 V. C. Tung, L.-M. Chen, M. J. Allen, J. K. Wassei, K. Nelson, R. B. Kaner and Y. Yang, Nano Lett., 2009, 9, 1949.

198 Y. Z. Chang, G. Y. Han, M. Y. Li and F. Gao, Carbon, 2011, 49, 5158.

199 S. Y. Yang, K. H. Chang, Y. F. Lee, C. C. M. Ma and C. C. Hu, Electrochem. Commun., 2010, 12, 1206.

200 Y. J. Li, Y. J. Li, E. B. Zhu, T. McLouth, C. Y. Chiu, X. Q. Huang and Y. Huang, J. Am. Chem. Soc., 2012, 134, 12326.

201 L. De Rogatis, M. Cargnello, V. Gombac, B. Lorenzut, T. Montini and P. Fornasiero, ChemSusChem, 2010, 3, 24.

202 W. I. Park, C.-H. Lee, J. M. Lee, N.-J. Kim and G.-C. Yi, Nanoscale, 2011, 3, 3522.

203 N. Li, M. Cao and C. Hu, Nanoscale, 2012, 4, 6205.

204 Y. Zheng, Y. Jiao, M. Jaroniec, Y. Jin and S. Z. Qiao, Small, 2012, 8, 3550.

205 G. Wu and P. Zelenay, Acc. Chem. Res., 2013, 46, 1878.

206 S. Cui, S. Mao, G. Lu and J. Chen, J. Phys. Chem. Lett., 2013, 4, 2441.

207 X. Xie, Y. Li, Z.-Q. Liu, M. Haruta and W. Shen, Nature, 2009, 458, 746.

208 M. Hamdani, R. N. Singh and P. Chartier, Int. J. Electrochem. Sci., 2010, 5, 556.

209 Y.-g. Wang, L. Cheng, F. Li, H.-m. Xiong and Y.-y. Xia, Chem. Mater., 2007, 19, 2095.

210 F. Cheng, Y. Su, J. Liang, Z. Tao and J. Chen, Chem. Mater., 2009, 22, 898.

211 Y. Liang, Y. Li, H. Wang, J. Zhou, J. Wang, T. Regier and H. Dai, Nat. Mater., 2011, 10, 780.

212 J. Xu, P. Gao and T. S. Zhao, Energy Environ. Sci., 2012, 5, 5333. 
213 Y. Liang, H. Wang, P. Diao, W. Chang, G. Hong, Y. Li, M. Gong, L. Xie, J. Zhou, J. Wang, T. Z. Regier, F. Wei and H. Dai, J. Am. Chem. Soc., 2012, 134, 15849.

214 J. Xiao, Q. Kuang, S. Yang, F. Xiao, S. Wang and L. Guo, Sci. Rep., 2013, 3, 2300.

215 S. Guo, S. Zhang, L. Wu and S. Sun, Angew. Chem., Int. Ed., 2012, 51, 11770.

216 Q. He, Q. Li, S. Khene, X. Ren, F. E. López-Suárez, D. Lozano-Castelló, A. Bueno-López and G. Wu, J. Phys. Chem. C, 2013, 117, 8697.

217 W.-H. Ryu, T.-H. Yoon, S. H. Song, S. Jeon, Y.-J. Park and I.-D. Kim, Nano Lett., 2013, 13, 4190.

218 J. Feng, Y. Liang, H. Wang, Y. Li, B. Zhang, J. Zhou, J. Wang, T. Regier and H. Dai, Nano Res., 2012, 5, 718.

219 T. N. Lambert, D. J. Davis, W. Lu, S. J. Limmer, P. G. Kotula, A. Thuli, M. Hungate, G. Ruan, Z. Jin and J. M. Tour, Chem. Commun., 2012, 48, 7931.

220 Y. Cao, Z. K. Wei, J. He, J. Zang, Q. Zhang, M. S. Zheng and Q. F. Dong, Energy Environ. Sci., 2012, 5, 9765.

221 Y. Cao, Z. Wei, J. He, J. Zang, Q. Zhang, M. Zheng and Q. Dong, Energy Environ. Sci., 2012, 5, 9765.

222 J. Zhang, C. Guo, L. Zhang and C. M. Li, Chem. Commun., 2013, 49, 6334.

223 J. Duan, Y. Zheng, S. Chen, Y. Tang, M. Jaroniec and S. Qiao, Chem. Commun., 2013, 49, 7705.

224 J.-S. Lee, T. Lee, H.-K. Song, J. Cho and B.-S. Kim, Energy Environ. Sci., 2011, 4, 4148.

225 J. Xiao, G. Xu, S.-G. Sun and S. Yang, Part. Part. Syst. Charact., 2013, 30, 893.

226 W. Zhang, Y. Zeng, C. Xu, H. Tan, W. Liu, J. Zhu, N. Xiao, H. H. Hng, J. Ma, H. E. Hoster, R. Yazami and Q. Yan, RSC Adv., 2012, 2, 8508.

227 X.-Y. Yan, X.-L. Tong, Y.-F. Zhang, X.-D. Han, Y.-Y. Wang, G.-Q. Jin, Y. Qin and X.-Y. Guo, Chem. Commun., 2012, 48, 1892.

228 S. Qiao, R. Zhou, Y. Zheng and D. Jurcakova, J. Mater. Chem. A, 2013, 1, 13179.

229 H.-G. Jung, Y. S. Jeong, J.-B. Park, Y.-K. Sun, B. Scrosati and Y. J. Lee, ACS Nano, 2013, 7, 3532.

230 Z.-S. Wu, S. Yang, Y. Sun, K. Parvez, X. Feng and K. Müllen, J. Am. Chem. Soc., 2012, 134, 9082.

231 V. Neburchilov, H. Wang, J. J. Martin and W. Qu, J. Power Sources, 2010, 195, 1271.

232 Y. Liang, H. Wang, J. Zhou, Y. Li, J. Wang, T. Regier and H. Dai, J. Am. Chem. Soc., 2012, 134, 3517.

233 H. L. Wang, Y. Yang, Y. Y. Liang, G. Y. Zheng, Y. G. Li, Y. Cui and H. J. Dai, Energy Environ. Sci., 2012, 5, 7931.

234 G. Zhang, B. Y. Xia, C. Xiao, L. Yu, X. Wang, Y. Xie and X. W. Lou, Angew. Chem., Int. Ed., 2013, 52, 8643.

235 D. U. Lee, B. J. Kim and Z. Chen, J. Mater. Chem. A, 2013, 1, 4754.

236 Y. Wang, D. Zhang and H. Liu, J. Power Sources, 2010, 195, 3135.

237 J. Wu, D. Zhang, Y. Wang, Y. Wan and B. Hou, J. Power Sources, 2012, 198, 122.

238 L. Zhang, J. Zhang, D. P. Wilkinson and H. Wang, J. Power Sources, 2006, 156, 171.
239 H. R. Byon, J. Suntivich and Y. Shao-Horn, Chem. Mater., 2011, 23, 3421.

240 M.-R. Gao, Y.-F. Xu, J. Jiang and S.-H. Yu, Chem. Soc. Rev., 2013, 42, 2986.

241 Y.-X. Zhou, H.-B. Yao, Y. Wang, H.-L. Liu, M.-R. Gao, P.-K. Shen and S.-H. Yu, Chem. -Eur. J., 2010, 16, 12000.

242 J. S. Jirkovský, A. Björling and E. Ahlberg, J. Phys. Chem. C, 2012, 116, 24436.

243 C. Zhao, D. Li and Y. Feng, J. Mater. Chem. A, 2013, 1, 5741.

244 H. Wang, Y. Liang, Y. Li and H. Dai, Angew. Chem., Int. Ed., 2011, 50, 10969.

245 N. Mahmood, C. Z. Zhang, J. Jiang, F. Liu and Y. L. Hou, Chem. -Eur. J., 2013, 19, 5183.

246 P. Chen, T.-Y. Xiao, H.-H. Li, J.-J. Yang, Z. Wang, H.-B. Yao and S.-H. Yu, ACS Nano, 2011, 6, 712.

247 Q. Liu, J. T. Jin and J. Y. Zhang, ACS Appl. Mater. Interfaces, 2013, 5, 5002.

248 Z.-G. Zhao, J. Zhang, Y. Yuan, H. Lv, Y. Tian, D. Wu and Q.-W. Li, Sci. Rep., 2013, 3, 2263.

249 W.-F. Chen, J. T. Muckerman and E. Fujita, Chem. Commun., 2013, 49, 8896.

250 J. Greeley, T. F. Jaramillo, J. Bonde, I. Chorkendorff and J. K. Norskov, Nat. Mater., 2006, 5, 909.

251 T. F. Jaramillo, K. P. Jørgensen, J. Bonde, J. H. Nielsen, S. Horch and I. Chorkendorff, Science, 2007, 317, 100.

252 A. B. Laursen, S. Kegnaes, S. Dahl and I. Chorkendorff, Energy Environ. Sci., 2012, 5, 5577.

253 B. Hinnemann, P. G. Moses, J. Bonde, K. P. Jørgensen, J. H. Nielsen, S. Horch, I. Chorkendorff and J. K. Nørskov, J. Am. Chem. Soc., 2005, 127, 5308.

254 Y. Li, H. Wang, L. Xie, Y. Liang, G. Hong and H. Dai, J. Am. Chem. Soc., 2011, 133, 7296.

255 P. Ge, M. D. Scanlon, P. Peljo, X. Bian, H. Vubrel, A. O'Neill, J. N. Coleman, M. Cantoni, X. Hu, K. Kontturi, B. Liu and H. H. Girault, Chem. Commun., 2012, 48, 6484.

256 L. Liao, J. Zhu, X. Bian, L. Zhu, M. D. Scanlon, H. H. Girault and B. Liu, Adv. Funct. Mater., 2013, 23, 5326.

257 Y.-H. Chang, C.-T. Lin, T.-Y. Chen, C.-L. Hsu, Y.-H. Lee, W. Zhang, K.-H. Wei and L.-J. Li, Adv. Mater., 2013, 25, 756.

258 H. I. Karunadasa, E. Montalvo, Y. Sun, M. Majda, J. R. Long and C. J. Chang, Science, 2012, 335, 698.

259 H. S. S. Ramakrishna Matte, A. Gomathi, A. K. Manna, D. J. Late, R. Datta, S. K. Pati and C. N. R. Rao, Angew. Chem., Int. Ed., 2010, 49, 4059.

260 Y. Shi, W. Zhou, A.-Y. Lu, W. Fang, Y.-H. Lee, A. L. Hsu, S. M. Kim, K. K. Kim, H. Y. Yang, L.-J. Li, J.-C. Idrobo and J. Kong, Nano Lett., 2012, 12, 2784.

261 E. G. S. Firmiano, M. A. L. Cordeiro, A. C. Rabelo, C. J. Dalmaschio, A. N. Pinheiro, E. C. Pereira and E. R. Leite, Chem. Commun., 2012, 48, 7687.

262 Q. Xiang, J. Yu and M. Jaroniec, J. Am. Chem. Soc., 2012, 134, 6575.

263 Y. Yan, B. Xia, X. Qi, H. Wang, R. Xu, J.-Y. Wang, H. Zhang and X. Wang, Chem. Commun., 2013, 49, 4884.

264 A.-M. Alexander and J. S. J. Hargreaves, Chem. Soc. Rev., 2010, 39, 4388. 
265 S. Yang, X. Feng, X. Wang and K. Müllen, Angew. Chem., Int. Ed., 2011, 50, 5339.

266 J. Tian, Q. Liu, C. Ge, Z. Xing, A. M. Asiri, A. O. Al-Youbi and X. Sun, Nanoscale, 2013, 5, 8921.

267 Y. Zheng, Y. Jiao, J. Chen, J. Liu, J. Liang, A. Du, W. Zhang, Z. Zhu, S. C. Smith, M. Jaroniec, G. Q. Lu and S. Z. Qiao, J. Am. Chem. Soc., 2011, 133, 20116.

268 X.-H. Li, J.-S. Chen, X. Wang, J. Sun and M. Antonietti, J. Am. Chem. Soc., 2011, 133, 8074.

269 Y. Zhang, T. Mori, L. Niu and J. Ye, Energy Environ. Sci., 2011, 4, 4517.

270 Y. Zheng, J. Liu, J. Liang, M. Jaroniec and S. Z. Qiao, Energy Environ. Sci., 2012, 5, 6717.

271 A. Du, S. Sanvito, Z. Li, D. Wang, Y. Jiao, T. Liao, Q. Sun, Y. H. Ng, Z. Zhu, R. Amal and S. C. Smith, J. Am. Chem. Soc., 2012, 134, 4393.

272 Y. Di, X. Wang, A. Thomas and M. Antonietti, ChemCatChem, 2010, 2, 834.

273 D. H. Youn, G. Bae, S. Han, J. Y. Kim, J.-W. Jang, H. Park, S. H. Choi and J. S. Lee, J. Mater. Chem. A, 2013, 1, 8007.

274 Q. Liu and J. Zhang, Langmuir, 2013, 29, 3821.

275 X. Wang, X. Chen, A. Thomas, X. Fu and M. Antonietti, Adv. Mater., 2009, 21, 1609.

276 X. Chen, J. Zhang, X. Fu, M. Antonietti and X. Wang, J. Am. Chem. Soc., 2009, 131, 11658.

277 M. Chisaka and H. Muramoto, ChemElectroChem, 2013, 1, 544.

278 Z. Wen, S. Cui, H. Pu, S. Mao, K. Yu, X. Feng and J. Chen, Adv. Mater., 2011, 23, 5445.

279 J. Jin, X. Fu, Q. Liu and J. Zhang, J. Mater. Chem. A, 2013, 1, 10538.
280 C.-W. Tsai, M.-H. Tu, C.-J. Chen, T.-F. Hung, R.-S. Liu, W.-R. Liu, M.-Y. Lo, Y.-M. Peng, L. Zhang, J. Zhang, D.-S. Shy and X.-K. Xing, RSC Adv., 2011, 1, 1349.

281 F. Jaouen, E. Proietti, M. Lefevre, R. Chenitz, J.-P. Dodelet, G. Wu, H. T. Chung, C. M. Johnston and P. Zelenay, Energy Environ. Sci., 2011, 4, 114.

282 S. Chen, J. Bi, Y. Zhao, L. Yang, C. Zhang, Y. Ma, Q. Wu, X. Wang and Z. Hu, Adv. Mater., 2012, 24, 5593.

283 Q. Liu, H. Zhang, H. Zhong, S. Zhang and S. Chen, Electrochim. Acta, 2012, 81, 313.

284 Y. J. Tong, Chem. Soc. Rev., 2012, 41, 8195.

285 C. H. Choi, M. W. Chung, H. C. Kwon, J. H. Chung and S. I. Woo, Appl. Catal., B, 2014, 144, 760.

286 Y. Li, W. Zhou, H. Wang, L. Xie, Y. Liang, F. Wei, J.-C. Idrobo, S. J. Pennycook and H. Dai, Nat. Nanotechnol., 2012, 7, 394.

287 P. Chen, T.-Y. Xiao, Y.-H. Qian, S.-S. Li and S.-H. Yu, Adv. Mater., 2013, 25, 3192.

288 J.-S. Lee, K. Jo, T. Lee, T. Yun, J. Cho and B.-S. Kim, J. Mater. Chem. A, 2013, 1, 9603.

289 G. Wu, N. H. Mack, W. Gao, S. G. Ma, R. Q. Zhong, J. T. Han, J. K. Baldwin and P. Zelenay, ACS Nano, 2012, 6, 9764.

290 J. Liang, X. Du, C. Gibson, X. W. Du and S. Z. Qiao, Adv. Mater., 2013, 25, 6226.

291 S.-L. Li and Q. Xu, Energy Environ. Sci., 2013, 6, 1656.

292 M. Jahan, Q. Bao and K. P. Loh, J. Am. Chem. Soc., 2012, 134, 6707.

293 M. Jahan, Z. Liu and K. P. Loh, Adv. Funct. Mater., 2013, 23, 5363.

294 T. K. Kim, J. Y. Cheon, K. Yoo, J. W. Kim, S.-m. Hyun, H. S. Shin, S. H. Joo and H. R. Moon, J. Mater. Chem. A, 2013, 1, 8432. 